Board of Governors of the Federal Reserve System

International Finance Discussion Papers

Number 1299

September 2020

\title{
The Stock Market Response to a "Regulatory Sine Curve"
}

Bo Sun, Xuan Tam, Eric Young

\begin{abstract}
Please cite this paper as:
Sun, Bo, Xuan Tam, Eric Young (2020). "The Stock Market Response to a "Regulatory Sine Curve"," International Finance Discussion Papers 1299. Washington: Board of Governors of the Federal Reserve System, https://doi.org/10.17016/IFDP.2020.1299.
\end{abstract}

NOTE: International Finance Discussion Papers (IFDPs) are preliminary materials circulated to stimulate discussion and critical comment. The analysis and conclusions set forth are those of the authors and do not indicate concurrence by other members of the research staff or the Board of Governors. References in publications to the International Finance Discussion Papers Series (other than acknowledgement) should be cleared with the author(s) to protect the tentative character of these papers. Recent IFDPs are available on the Web at www.federalreserve.gov/pubs/ifdp/. This paper can be downloaded without charge from the Social Science Research Network electronic library at www.ssrn.com. 


\section{The Stock Market Response to a "Regulatory Sine Curve"*}

\author{
Bo Sun
}

Federal Reserve Board
Xuan Tam

City University of Hong Kong
Eric Young

University of Virginia

${ }^{*}$ We thank seminar participants at the Federal Reserve Board, Carnegie Mellon University, University of Virginia, Peking University, Tsinghua PBOC School of Finance, the LAEF Conference, the Midwest Macroeconomics Meetings, and the SED Meetings for helpful comments. Please direct all correspondence to Bo Sun, Email: bo.sun@frb.gov. The latest version of the paper is available at https://sites.google.com/site/bosun09/research. Young thanks the Bankard Fund for Political Economy at Virginia, the Batten Institute at the Darden School of Business, and LAEF at Santa Barbara for financial support. The views expressed herein are the authors' and do not necessarily reflect the opinions of the Board of Governors of the Federal Reserve System. 


\title{
The Stock Market Response to a "Regulatory Sine Curve"
}

\begin{abstract}
We construct new indicators of financial regulatory intensity and find evidence that a "regulatory sine curve" generally exists: regulatory oversight increases following a recession and wanes as the economy returns to normalcy. We then build an asset pricing model, based on the idea that regulatory oversight both deters incentives to commit fraud ex ante and reveals hidden negative information ex post. Our calibration suggests that these mechanisms can be quantitatively important for stock price dynamics.
\end{abstract}

Keywords: Cyclical financial regulation, Stock crash risk, Gradual boom and sudden crash. JEL Classifications: G12, G30, K20. 
"Only when the tide goes out do you discover who's been swimming naked."

- Warren Buffett

\section{Introduction}

Commentators claim that a "regulatory sine curve" governs the oversight exercised by financial regulators; specifically, regulatory intensity increases after a recession and wanes as the economy returns to normalcy. ${ }^{1}$ We seek to investigate this claim by constructing an indicator of financial regulatory intensity to analyze how it evolves over time and later assess how it affects asset prices.

Existing datasets on financial regulatory actions only cover a relatively short period (typically starting from the late 1990s) and are piecemeal in nature. To investigate whether the intensity of financial regulation is systematically related to the underlying economic conditions, we begin by constructing a new index of financial regulatory intensity (FRI) using a semantic search approach that measures newspaper coverage on financial regulatory oversight. To differentiate from the law-making aspect (i.e., initiation or enhancement of regulatory rules), we also construct a subindex of FRI that specifically captures variation in implementation of financial regulation — that is, the frequency of regulatory investigations. Both FRI and the subindex exhibit a strong negative relationship with the aggregate state of the economy: they spike during the Great Depression, the post dot-com bubble recession in 2001, and the recent Great Recession; more generally, the indexes are typically higher during NBER recession than in normal times and are negatively correlated with the GDP growth rate.

We then propose a model to study the implications of cyclical regulatory oversight for stock market dynamics. Regulatory oversight can play an important role in determining the information present in financial markets for two reasons. First, investigations detect fraud ex post and reveal hidden, accumulated negative information. Second, anticipated regulatory investigations will impose adverse consequences for firms and thus help limit managerial incentives to manipulate performance ex ante. In our model, regulators conduct investigations to detect fraud with a tendency that leaves more discretion to managers in booms than during downturns.

\footnotetext{
${ }^{1}$ See, for example, "The Political Economy of Dodd-Frank" by John Coffee, Harvard Law School Forum on Corporate Governance and Financial Regulation, March 12, 2012.
} 
We conduct this exercise within a Lucas asset-pricing model that is standard in all aspects, except that a manager reports the firm's earnings, which may be subsequently examined by regulators. There is a continuum of newly hired managers in each period, each operating a firm. Managers may possibly have discretion over the firm earnings reported to the investors, which are paid to investors as dividends. Manipulation occurs when reported earnings differ from the true value. Regulators investigate a fraction of the firms each period, and if manipulation is detected, investors bear monetary losses depending on the scale of accumulated manipulation. The key feature we focus on here is that the fraction of firms being investigated depends on the aggregate state of the economy. The investors are assumed to be risk-neutral; thus, the price of a firm in each period is given by discounted expected future dividends net of financial losses associated with manipulation.

In our model of asset pricing, cyclical regulatory oversight delivers countercyclical stock crash risk and raises both the frequency and severity of stock crashes through two reinforcing mechanisms. A direct impact of cyclical regulation on stock dynamics works through information revelations: lack of oversight in good times leaves financial information manipulation undetected and renders stock fluctuations mild, while strengthened regulation during economic downturns reveals and penalizes accumulated fraud, causing stocks to decline sharply. There is also an indirect impact of financial regulation via managerial incentives. Loosened regulation during booms helps fuel managerial incentives to overstate firm performance. The increased noise in financial information further mutes stock movements in good times, while it causes downturns even sharper when the accumulated losses are revealed all at once. Although most stock crashes occurred in recessions, we argue that the seeds were actually sown during booms.

By the same token, cyclical regulatory activities also contribute to gradual booms and sudden crashes in the financial markets through both information revelation and incentive distortions. The asymmetric regulatory responses to business cycles cause more negative information to be revealed in large lumps during bad times, resulting in sharp downward stock movements. As limited investigations during upturns leave uncertainties in financial information unresolved, investors discount the potentially fraudulent performance, slowly updating their beliefs about corporate outlooks in booms. In addition, loosened regulation encourages manipulation and corrodes reporting quality in booms, further mitigating investors' response to positive corporate news in good times and also causing more aggressive manipulation to be revealed during periods of stress.

Finally, we study the pattern of asymmetry in stock prices more formally, using tests of "time 
irreversibility" developed by Ramsey and Rothman (1996). Time irreversibility is generated either by (i) nonlinear data-generating processes or (ii) non-Gaussian innovations; the tests examine whether the bicovariances between current and past realizations are symmetric. ${ }^{2} \mathrm{We}$ find evidence of irreversibility in stock prices both in the data and in the model, and the pattern of bicovariance signs are broadly consistent as well. In particular, we find evidence of the "slow-boom sudden-crash" dynamics that are the focus of Veldkamp (2005) and van Nieuwerburgh and Veldkamp (2006). In those papers, slow booms and sudden crashes are the result of procyclical information - with lots of firms producing during expansions, agents can obtain a better estimate of the aggregate state. As a complementary explanation, in our model information about each individual firm is of lower quality during expansions (while the aggregate state is public information), because managers are more able to actively hide idiosyncratic failures.

Although ours is the first article that we are aware of that ties changing regulatory oversight to asset price movements, there are a number of articles that are related to the spirit of our analysis, which is the role of institutions in monitoring and mitigating information asymmetries. A recent paper by Chen and Zha (2015) estimates the time-varying monitoring efficiency modeled in Greenwood, Sanchez, and Wang (2010) - that is, banks' ability to detect if borrowing firms misreport. A growing body of work examines "credit cycles" - the idea that banks and other credit suppliers engage in behavior that exacerbates business cycle effects, making credit even tighter in recessions and looser in expansions (Bernanke and Gertler, 1989; Kiyotaki and Moore, 1997; Ruckes, 2004). Albuquerque and Wang (2008) study the asset pricing and welfare implications of imperfect investor protection and assess the magnitude of both the loss of investor welfare and the reduction in market value due to managerial over-investment. None of these articles, however, address cyclical patterns of regulatory oversight, which is our key focus.

The rest of the paper proceeds as follows. Section 2 provides new evidence on the cyclical properties of the intensity of financial regulatory oversight. Section 3 discusses the problem of a regulator determining investigation intensities, keeping in mind how their policies influence the behavior of managerial manipulation. The one-period model highlights the link between information manipulation, regulatory intensities, and aggregate economic conditions. Section 4 embeds this regulator-manager interaction into an infinite-horizon economy to examine the implied properties for asset pricing. Section 5 presents the results and mechanisms of a calibrated

\footnotetext{
${ }^{2} \mathrm{~A}$ bicovariance is the covariance between a random variable and the square of another.
} 
version of the model. Section 6 concludes. All technical details are in the Appendix.

\section{Cyclical Patterns of Financial Regulatory Oversight}

Casual observations suggest that financial regulation tends to tighten during economic downturns. ${ }^{3}$ For example, the Glass-Steagall Act, passed in 1932 during the Great Depression, was gradually repealed over several decades, culminating with the Graham-Leach-Bliley Act of 1999 while the U.S. economy was experiencing the Great Moderation and the late 1990s tech boom. In addition to the rule-making aspect of financial regulation, the implementation and enforcement of existing rules are at the discretion of federal regulators and may vary systematically over time, which arguably have more direct, real-time information implications. Consistently, it has been argued that a boom can encourage and conceal misrepresentation by firms, which are then revealed by the ensuing recession. ${ }^{4}$ The long boom of the 1990s was followed, first by recession, then by revelations of financial chicanery at many of America's largest companies. A wave of fraud revelations again clustered at the beginning of the recent economic turmoil in 2008. Relatedly, Bertomeu and Magee (2011) show that the quality of financial reporting and probability of revelations are minimal prior to a recession and increase during and after a recession. $^{5}$

Despite growing interest in the effects of financial regulation, the academic literature does not contain a sufficiently long time series that characterizes financial regulatory behavior. To examine whether a "regulatory sine curve" exists, we construct a new index of financial regulatory intensity by using a text-analysis approach similar to Baker, Bloom, and Davis (2017) to measure the frequency of newspaper coverage on financial regulatory actions, and examine its evolution since 1900 .

Using ProQuest Newsstand and historical archives, we construct an index by searching from January 1900 onward for articles containing 'regulation' or 'regulatory,' 'financial' or 'finance,' and one or more of the following terms: 'Congress,' 'Federal Reserve/Fed,' 'SEC/Security and Exchange Commission,' 'OCC/Office of the Comptroller of the Currency,' 'FDIC/Federal Deposit Insurance Corporation,' and 'stock exchange.' To meet our criteria, articles must

\footnotetext{
${ }^{3}$ Timothy Geithner, "Stress Test," 2015.

${ }^{4}$ See Povel, Singh, and Winton (2007), Brunnermeier et al. (2009), and McDonnell (2013).

${ }^{5}$ Empirical evidence for cyclical bias in bank examination, both in terms of frequency and rating stringency, is also mounting. See, for example, Syron (1991), Berger, Kyle, and Scalise (2001), and Laeven and Majnoni (2003).
} 
Table 1: The relationship between FRI/FRI subindex and the aggregate economy

\begin{tabular}{|cccc|}
\hline & GDP growth & Aggregate earnings & Weighted average earnings per share \\
\hline FRI & $-9.098^{* * *}$ & $-8.15^{* * *}$ & $-264.099^{* * *}$ \\
FRI subindex & $-7.284^{* * *}$ & $-10.29^{* * *}$ & $-366.384^{* * *}$ \\
\hline
\end{tabular}

include all three categories pertaining to financial regulation. To gauge how stringently existing regulatory rules are enforced, we also construct a sub-index specifically for implementation of financial regulation that counts the share of articles containing, in addition to the above search terms, one or more of the following terms: 'enforcement,' 'lawsuit,' 'penalties,' 'fines,' 'investigation,' 'examination,' 'civil charges,' 'criminal charges,' 'manipulation,' 'fraud,' and 'supervision.' We do this for each day's edition of the Washington Post, Wall Street Journal, and New York Times. The indexes are normalized by the total number of news articles in each newspaper, and are aggregated by summing the resulting series and scaling them to have a mean of 100 over the sample. The Appendix provides a detailed description of the index construction.

Figure 1 displays our Financial Regulation Index since 1900. The first striking feature is the strong time trend. It suggests that over the last century, an increasingly larger fraction of newspaper articles have references to financial regulation, possibly because the financial industry has been growing bigger as a fraction of the entire economy during the last century. The second feature is that the indexes co-move with aggregate economic conditions. For example, they spike during the Great Depression, the post dot-com bubble recession in 2001, and the recent Great Recession. More generally, the indexes are typically higher during NBER recessions than in normal times. Figure 2 plots the Financial Regulation Intensity (FRI) index and the FRI subindex against the GDP growth rate. It demonstrates a strong negative correlation, with a correlation coefficient of -0.566 after 1985 for the overall index and -0.603 for the subindex. We also report in Table 1 the results from binary regressions of FRI and FRI subindex on several measures of the aggregate state of the economy at an annual frequency from 1960 through 2016. We provide additional evidence for cyclical regulatory behavior in the Appendix.

To further examine the response of financial regulatory intensity to changes in the real economy, we study impulse response functions estimated using a standard Cholesky decomposition, 
with the following recursive VAR structure:

$$
\mathbf{Y}_{t}=\left[i p_{t}, p_{t}, i_{t}, e p u_{t}, f r i_{t}\right],
$$

where ip denotes the log industrial production, $p$ the log S\&P 500 stock market index price, $i$ the T-bill rate, epu the EPU index of Baker, Bloom, and Davis (2017), and fri our index of financial regulatory intensity. To be conservative, we start by ordering the FRI index last, allowing IP, S\&P 500, T-bill, and EPU to contemporaneously affect the intensity of financial regulation. Recognizing the arbitrariness of Cholesky ordering in VARs that involve financial variables, we check and confirm robustness to all alternative orderings. The results are highly robust to timing assumptions and are displayed in the Appendix.

Figure 3 shows the impulse responses following a one standard deviation surprise decrease in IP. The panels report the estimated impulse responses along with 68 percent confidence bands, computed using bootstrapping methods. The intensity of financial regulator oversight, measured by both FRI and sub-FRI indexes, rises significantly on impact, before reverting back to trend in 10 months (average length of NBER recessions). The other responses to a negative IP shock, including the stock market decline, loosening monetary policy, and rises in EPU, are consistent with the standard results in the literature.

The methodology used to compute FRI indexes follows the one Baker, Bloom, and Davis (2017) use to construct the economic policy uncertainty index (EPU). However, the two sets of indexes measure different economic variables and are characterized by distinct features. Our Financial Regulation Indexes capture a first-moment concept, that is, the level of financial regulatory oversight, while the second-moment movement — i.e., the "uncertainty" aspect is the focus of Baker, Bloom, and Davis' EPU index. For example, EPU spiked in response to 9/11, Gulf War II, the debt ceiling dispute of 2011, and the 2012 fiscal cliff dispute, all of which FRIs are not responsive to. While national security threats or monetary policy shocks generate uncertainty about government policy overall, they do not have direct implications for the level of regulatory oversight.

Using the impulse response approach above that controls for EPU, we turn to examining the effects of shocks to FRI. This analysis also helps us illuminate the distinction between our measure and EPU: with EPU in our system, we examine any residual effect financial regulatory intensity has beyond that of overall economic policy uncertainty. Figure 4 shows the impulse responses following a surprise increase in FRI of one standard deviation, about 12 points. The panels report the estimated impulse responses along with 68 percent confidence 
bands, computed using bootstrapping methods. EPU rises in response to tightened financial regulatory intensity. Both IP and the stock market index fall on impact and reach a trough after about half a year, before reverting to trend. The T-bill rate eventually falls, perhaps induced by the central bank responding by lowering the policy rate. We also check and confirm robustness to all alternative orderings, as shown in the Appendix.

In this section we construct indicators of financial regulatory oversight using semantic analysis and show that a "regulatory sine curve" generally exists: the intensity of regulatory oversight increases following downturns and weakens as the economy returns to normalcy. In Section 3 we use a model of regulatory-manager interaction to micro-found the cyclicality in regulatory intensity, which will be embedded in an asset pricing framework in Section 4.

\section{Regulator-manager interaction}

Here we present a simple model that highlights mechanisms that could give rise to countercyclical regulatory oversight, which in turn affects managerial incentives to commit fraud. The key parameter will govern the choice of regulatory intensity - how often regulators detect fraudulent reporting. This model will micro-found the cyclical bias in both regulatory detections of fraud and the prevalence of fraud that will be embedded in an asset pricing framework.

We assume that there is a continuum of firms, each being run by a manager. Firms' true earnings are jointly determined by an aggregate and an idiosyncratic state in each period. There are two values for the aggregate state $a \in\{g, b\}$ with $g>b$ ("good" and "bad"), and two values for the idiosyncratic state $y \in\{h, l\}$ with $h>l$ ("high" and "low"). Each firm's earnings are then given by ay. The aggregate state is perfectly and costlessly observed by both the regulator and the firm manager, whereas the idiosyncratic state is the private information of the manager; manipulation occurs when the manager reports a high value of earnings when the true value is low. ${ }^{6}$

\footnotetext{
${ }^{6}$ Feroz, Park, and Pastena (1991) document that most SEC enforcement actions are aimed at overstatements, the average amount of restatements is negative, and over 75 percent of restatements are negative. Our model thus focuses on upward manipulation.
} 


\begin{tabular}{lllll}
\hline States realize: & Regulator & Manager & Possible & Actual \\
$a$ (public info) & commits to & reports: $r$ & $\begin{array}{l}\text { investigations } \\
\text { cash flows }\end{array}$ \\
$y$ (private info) & investigation & & take place & \\
& frequency: $\tau$ & & &
\end{tabular}

The timeline in the above figure chronicles the sequence of events in the model. At the beginning of each period, an aggregate state $(a)$ is perfectly revealed to all agents, and each firm's idiosyncratic state $(y)$ is privately observed by the manager. The regulator commits to a regulatory policy in the current period, which boils down to a frequency of investigations $(\tau)$. Each manager subsequently makes a report of the idiosyncratic state $(r)$, and investigation follows if there is any. We assume (without modeling the details such as credit conditions and collateral constraints) that the manager is unable to hide manipulation and will get caught if investigated in bad aggregate state (i.e., $a=b)$. When the aggregate state is good $(a=g)$, with probability $1-\varepsilon$, the manager is able to finance the discrepancy in the report and conceal manipulation when investigated (and therefore escape punishment); with probability $\varepsilon$ this financing will not be possible and will be charged with fines $F(m)$, where $m$ is the amount of misstated earnings. Here, as a shorthand for a range of factors that can contribute to the cyclicality in regulatory oversight, we build in a state-dependent probability of detection given investigation, by directly assuming it to be higher during recessions. ${ }^{7}$ We denote earnings report by $R(y)=r \in\{\tilde{h}, \tilde{l}\}$ : we denote high and low reports by $\widetilde{h}$ and $\widetilde{l}$ respectively to distinguish them clearly from realized values $h$ and $l$.

The regulator chooses the frequency of investigations $\tau$ to minimize the prevalence of fraud subject to the cost of investigation, given by $C(\tau)=\frac{1}{2} C \tau^{2}$, where $C \geq 0$. Managers differ according to the private utility they receive from reported earnings - a report of $r$ delivers $\theta$ ar utils to the managers, where $\theta \sim U N I[0,1]$, as managers may have different valuations of manipulating earnings, including variation in pay-performance sensitivity, preferences, and the complexity of business operations. The value of $\theta$ is the manager's private information.

The Bayesian Nash equilibrium is characterized by $\tau(g)<\tau(b)$ and $x(g)>x(b)$ (solved

\footnotetext{
${ }^{7}$ Managers have incentives to manipulate performance by hiding temporary losses to avoid disclosing negative information about the firm. During booms, cash flows from corporate operations and external credit are readily available to absorb losses and thus prevent fraud from being revealed. In downturns, however, liquidity cushion tends to evaporate and managers may lose access to these funds, finding it more difficult to obscure reporting discrepancies. As Warren Buffett put it, "Only when the tide goes out do you discover who's been swimming naked."
} 
in the Appendix). Managerial incentives to misreport vary with the aggregate state $(a)$ as the variation in $\tau$ and $p(a)$ implies that detection is lower in good times. These implications are consistent with the empirical literature that documents a greater tendency by firms to manipulate earnings upwards during upturns (e.g., Wang, Winton, and Yu, 2010; Cohen and Zarowin, 2012).

Our model generates the following features relevant for asset pricing. First, cyclical patterns in managerial manipulation emerge in response to a cyclical bias in regulatory actions: a boom encourages and conceals fraud. Second, rational investors who are informed about the regulatormanagers interaction are uncertain about whether a particular report has been inflated. That is, investors can perfectly infer $x$ given the equilibrium regulatory policy, but they cannot unambiguously gauge firms' idiosyncratic state $(y)$. We show in the next section that the relationship between investigation intensity and manipulation frequency — together with the unrevealing financial reporting caused by manipulation — has considerable implications for the dynamics of financial markets.

\section{Cyclical Regulation and Asset Pricing}

We now embed the mechanisms identified in Section 3 into a dynamic model of asset pricing. We introduce risk-neutral investors who price stocks based on earnings reports, understanding that these reports may have been manipulated and investigation probabilities move cyclically. Specifically, three central features generated in our model of regulation will be embedded in an infinite-horizon economy to examine the implied properties of stock returns: (i) regulatory investigations that reveal hidden negative information are cyclical; (ii) manipulation tendencies are influenced by cyclical regulatory behavior and exhibit cyclicality as well; and (iii) investors can infer the likelihood of manipulation $(x)$ given the equilibrium regulatory policy, but cannot unambiguously gauge the true state of each firm. Note that $x(a)$ and $\lambda(a)$ were endogenous in the previous section; here, we adopt a reduced-form approach in the pricing analysis using calibrated values of $x(a)$ and $\lambda(a)$.

\subsection{Setup}

The economy is populated by a continuum of managers who are hired by investors to operate firms; these managers make reports regarding earnings as in Section 3. The aggregate state $a$ 
again takes on two values, $g$ and $b$, with a transition matrix

$$
\operatorname{Pr}\left(a_{t+1}=j \mid a_{t}=i\right)=\pi_{i j}
$$

Individual firm productivity takes on two values, $h$ and $l$, with a transition matrix

$$
\operatorname{Pr}\left(y_{t+1}=j \mid y_{t}=i\right)=\varpi_{i j}
$$

We will assume both processes are positively autocorrelated $\left(\pi_{h h}>\pi_{h l}\right.$ and $\left.\pi_{l l}>\pi_{l h}\right)$ and symmetric $\left(\pi_{h h}=\pi_{l l}\right)$. Total earnings are given by $a_{t} y_{t}$.

The timeline of the model events in each period is described in the figure below. Each period begins with the realization of $a_{t}$, which again is public information (observable to managers, regulators, and investors). The idiosyncratic value $y_{t}$ is privately observed by the managers, who then make their report $r_{t}$. The probability of detection by regulators (given manipulation) is given by $\lambda\left(a_{t}\right)$, where $\lambda(g)<\lambda(b)$.

\begin{tabular}{llllll}
\hline States realize: & Regulator & Manager & Asset price & Possible & Dividends \\
$a_{t}$ (public info) & commits to & reports $r_{t}$ & based on & investigations & are paid \\
$y_{t}$ (private info) & $\begin{array}{l}\text { investigation } \\
\text { frequency: } \tau_{t}\end{array}$ & & $a_{t}, r_{t}$ & take place; & \\
& & and others & investors & \\
& & & bear losses &
\end{tabular}

\subsection{Investor Learning and Price Formation}

Investors are risk neutral and own the firms; the price of firm equity is then given by the present value of expected future dividends net of expected financial loss associated with detected manipulation. For notational convenience, we denote reports by $\widetilde{h}$ and $\widetilde{l}$ to distinguish them clearly from realized values $h$ and $l$. Recall that $R(h)=\widetilde{h}$ (high productivity always generates a high report), $R(l)=\widetilde{h}$ with probability $x(a)$, and $R(l)=\widetilde{l}$ with probability $1-x(a)$. Calculating the posterior probability that actual earnings were high involves assessing the entire history of reports, back to the most recent detection, because the financial losses that investors bear are proportional to the number of manipulated reports; thus, when the manager makes a report, investors reassess all past reports as well as the current one.

We denote the current stock price by $q_{t}$. The relevant information in the report history can be summarized by a small set of state variables. In particular, we can price assets using the following set of state variables (for detailed examples of what each state variable represents, see the Appendix): 
- $a$ : the current aggregate state;

- $\gamma$ : the conditional probability (based on information in the current report) that $y_{t}=h$;

- $Z$ : the expected number of periods involving false reports between the last detection and the most recent low report (note that $Z=0$ if there is no low report between the last detection and the current period);

- $N$ : the number of consecutive high reports since the last low report or the last detection, whichever is more recent;

- $r$ : the current report;

- $\bar{y}$ : the true earnings before the series of $N$ consecutive high reports starts.

Thus, $q_{t}=Q\left(a_{t}, \gamma_{t}, Z_{t}, N_{t}, r_{t}, \bar{y}_{t}\right) .{ }^{8}$ Current idiosyncratic state is revealed in two circumstances. First, low reports are known to be truthful, meaning investors know the current value of $y_{t}$. Second, fraud detection occurs, revealing the entire history of $y_{t}$. The distinction will be important for pricing assets - a low report implies low productivity (albeit truthful) today, which will lead to downward revisions of past reports, because $y_{t}$ is positively autocorrelated; while detection reveals all past reports. The law of motion for $\gamma$ follows Bayes' rule:

$$
\gamma_{t+1}^{a}= \begin{cases}\frac{\gamma \varpi_{h h}+(1-\gamma) \varpi_{l h}}{\mu_{a}} & r_{t+1}=\widetilde{h} \\ 0 & r_{t+1}=\widetilde{l}\end{cases}
$$

where

$$
\mu_{a}=\gamma \varpi_{h h}+(1-\gamma) \varpi_{l h}+\gamma\left(1-\varpi_{h h}\right) x(a)+(1-\gamma)\left(1-\varpi_{l h}\right) x(a)
$$

is the conditional probability that a manager makes a high report next period in aggregate state $a$.

A high report in aggregate state $a_{t}$ implies

$$
Q\left(a_{t}, \gamma_{t}, Z_{t}, N_{t}, \widetilde{h}, \bar{y}_{t}\right)=a_{t} \widetilde{h}+\left(1-\lambda\left(a_{t}\right)\right) W_{n a}^{\widetilde{h}}+\lambda\left(a_{t}\right) W_{d a}^{\widetilde{h}}
$$

\footnotetext{
${ }^{8}$ In Sun (2014), the information in a history of possibly manipulated reports is characterized by a similar set of state variables. We extend Sun (2014) to incorporate state-dependent manipulation and detection, that is, the likelihood of both manipulation and detection vary systematically with the aggregate state.
} 
where $W_{n a}^{r}$ is the expected future value of the stock if detection does not occur in the current period, and $W_{d a}^{r}$ is the expected value if detection takes place. Both future values are conditioned on the report and the current aggregate state. If no detection takes place, then

$$
\begin{gathered}
W_{n a}^{\widetilde{h}}=\beta \pi_{a g}\left[\mu_{g} Q\left(g, \gamma_{t+1}^{g}, Z_{t}, N_{t}+1, \widetilde{h}, \bar{y}_{t}\right)+\left(1-\mu_{g}\right) Q\left(g, 0, Z_{t}, N_{t}+1, \widetilde{l}, \bar{y}_{t}\right)\right]+ \\
\beta \pi_{a b}\left[\mu_{b} Q\left(b, \gamma_{t+1}^{b}, Z_{t}, N_{t}+1, \widetilde{l}, \bar{y}_{t}\right)+\left(1-\mu_{b}\right) Q\left(b, 0, Z_{t}, N_{t}+1, \widetilde{l}, \bar{y}_{t}\right)\right]
\end{gathered}
$$

In contrast, if the firm is being investigated, then

$$
\begin{aligned}
& W_{d a}^{\widetilde{h}}=-\kappa\left[Z_{t}+f\left(N_{t}+1, \bar{y}_{t}\right)\right]+ \\
& \beta \pi_{a g}\left[\begin{array}{c}
\gamma\left[\xi_{1 g} Q\left(g, \frac{\varpi_{h h}}{\xi_{1 g}}, 0,0, \widetilde{h}, h\right)+\left(1-\xi_{1 g}\right) Q(g, 0,0,0, \widetilde{l}, h)\right]+ \\
(1-\gamma)\left[\xi_{2 g} Q\left(g, \frac{\varpi_{l h}}{\xi_{2 g}}, 0,0, \widetilde{h}, l\right)+\left(1-\xi_{2 g}\right) Q(g, 0,0,0, \widetilde{l}, l)\right]
\end{array}\right]+ \\
& \beta \pi_{a b}\left[\begin{array}{c}
\gamma\left[\xi_{1 b} Q\left(b, \frac{\varpi_{h h}}{\xi_{1 b}}, 0,0, \widetilde{h}, h\right)+\left(1-\xi_{1 b}\right) Q(b, 0,0,0, \widetilde{l}, h)\right]+ \\
(1-\gamma)\left[\xi_{2 b} Q\left(b, \frac{\varpi_{l h}}{\xi_{2 b}}, 0,0, \widetilde{h}, l\right)+\left(1-\xi_{2 b}\right) Q(b .0,0,0, \widetilde{l}, l)\right]
\end{array}\right] .
\end{aligned}
$$

Here, $\xi_{1 a}$ is the conditional probability of getting a high report tomorrow when the aggregate state tomorrow is $a$, given the current idiosyncratic state is high, and $\xi_{2 a}$ is the probability of the high report tomorrow given the current idiosyncratic state is low:

$$
\begin{aligned}
& \xi_{1 a}=\varpi_{h h}+\left(1-\varpi_{h h}\right) x(a), \\
& \xi_{2 a}=\varpi_{l h}+\left(1-\varpi_{l h}\right) x(a) .
\end{aligned}
$$

The first term in Equation (2) is the expected monetary loss for detected manipulation, composed of three parts. $\kappa$ is the financial loss per manipulated earnings report. As noted above, $Z_{t}$ is the expected number of reports involving manipulation between the last detection and the most recent low report. $f\left(N_{t}+1, \bar{y}_{t}\right)$ is the expected number of falsified reports amoung the $N_{t}+1$ consecutive high reports that have occurred since the last low report or the last detection, whichever is more recent. ${ }^{9}$

If the current report is low the price is simpler, since it does not involve the possibility of current manipulation and therefore does not depend on $\gamma$ :

$$
Q\left(a_{t}, 0, Z_{t}, N_{t}, \bar{y}_{t}\right)=a_{t} \widetilde{l}+\left(1-\lambda\left(a_{t}\right)\right) W_{n a}^{\widetilde{l}}+\lambda\left(a_{t}\right) W_{d a}^{\widetilde{l}}
$$

\footnotetext{
${ }^{9}$ The derivation of $f$ immediately follows that in Sun (2014), and is derived in the Appendix for clarity.
} 
note that even though the current report is low, the firm may well have misrepresented past earnings and therefore may still be investigated. The two expected value terms are

$$
\begin{gathered}
W_{n a}^{\widetilde{\imath}}=\beta \pi_{a g}\left[\xi_{g} Q\left(g, \frac{\varpi_{l h}}{\xi_{g}}, Z_{t}, 0, \widetilde{h}, l\right)+\left(1-\xi_{g}\right) Q\left(g, 0, Z_{t}, 0, \widetilde{l}, l\right)\right]+ \\
\beta \pi_{a b}\left[\xi_{b} Q\left(b, \frac{\varpi_{l h}}{\xi_{b}}, Z_{t}, 0, \widetilde{h}, l\right)+\left(1-\xi_{b}\right) Q\left(b, 0, Z_{t}, 0, \widetilde{l}, l\right)\right]
\end{gathered}
$$

and

$$
\begin{aligned}
& W_{d a}^{\tilde{l}}=-\kappa\left[Z_{t}+f\left(N_{t}, \bar{y}_{t}\right)\right]+ \\
& \beta \pi_{a g}\left[\xi_{g} Q\left(g, \frac{\varpi_{l h}}{\xi_{g}}, 0,0, \widetilde{h}, l\right)+\left(1-\xi_{g}\right) Q(g, 0,0,0, \widetilde{l}, l)\right]+ \\
& \beta \pi_{a b}\left[\xi_{b} Q\left(b, \frac{\varpi_{l h}}{\xi_{b}}, 0,0, \widetilde{h}, l\right)+\left(1-\xi_{b}\right) Q(b, 0,0,0, \widetilde{l}, l)\right],
\end{aligned}
$$

where

$$
\xi_{a}=\varpi_{l h}+\left(1-\varpi_{l h}\right) x(a)
$$

is the conditional probability of a high report tomorrow (note that since current state is known to be low, we do not need two different probabilities here). It is a straightforward application of the Banach fixed point theorem to show that $Q$ exists and is unique. We define the gross return on a stock as reported earnings minus penalties (interpreted as the dividend) plus the current stock price, divided by the lagged stock price.

These expressions permit us to compute the price recursively. We now proceed to show the mechanisms and results of the model in a calibrated exercise.

\section{Quantitative Exercise}

In this section we use numerical methods to study the implications of our model for stock prices. We first present our calibration and display the equilibrium functions. Then we discuss the model's implications for stock crashes, volatility, and return skewness. Finally we turn to a study of time irreversibility.

\subsection{Calibration}

To calibrate our model we simulate a panel of 500 firms for 2000 periods; we choose the model parameters to match a specified set of facts using this simulated panel. We obtain information 
on firm earnings from Compustat quarterly data from Q1 1970 to Q4 2017. We calibrate the Markov process of the aggregate state following Krusell and Smith (1998). Given the aggregate state process, we use the Tauchen method to calibrate the transition probabilities and binary levels of the idiosyncratic productivity to match the mean and standard deviation of the S\&P Composite deflated scaled earnings. The discount factor $\beta$ is set to be 0.98 (a quarterly interest rate of 2 percent). For the cost of being detected manipulating earnings $(\kappa)$, Karpoff, Lee, and Martin (2008) estimate that for each dollar of misreported earnings, a firm loses 4.08 dollars when manipulation is revealed; thus, we set $\kappa=4.08(h-l)$.

To set $\lambda(g)$ and $\lambda(b)$, we use the average number of firms subject to legal action during NBER expansions and recessions. For $x(a)$ and $x(b)$, we follow the results in Cohen and Zarowin (2007). Cohen and Zarowin (2007) estimate the relation between the percentage of firms manipulating earnings and the industrial production growth rate, and show that managerial manipulation is positively associated with aggregate economic conditions. We use their coefficient estimates to compute the manipulation likelihood in our calibrated model. ${ }^{10}$ Table 1 summarizes the parameter choices.

Figure 5 shows the function $f(N, \bar{y})$; the expected number of inflated reports rises monotonically with $N$ for an initial low report, and displays a small downward segment between $N=1$ and $N=2$ for an initial high report. Figures 6-8 show how the pricing function $Q$ varies with $(f, \gamma, Z)$ across different reports. As the monetary loss associated with detected manipulation is a linear function of the number of restated financial statements, the price in response to a high report is linearly increasing in $\gamma$ and linearly decreasing in $Z$. The price in response to a low report is also linearly decreasing in $Z$, with $\gamma$ updated to 0 .

\footnotetext{
${ }^{10}$ In estimating the relation between firm manipulation and the aggregate state of the economy, Cohen and Zarowin (2007) identify the percentage of firms manipulating reports by estimating the tendency of firms to meet or beat the following three benchmarks: the consensus analyst forecast for the quarter, a positive earnings change for the current quarter compared to the same quarter last year, and positive earnings less than or equal to $.5 \%$ of total assets. For the aggregate state of the economy, they use the GDP growth rate, the industrial production growth rate, and the aggregate $\mathrm{P} / \mathrm{E}$ ratio, all of which point to a positive relation between manipulation likelihood and aggregate state.
} 
Table 1

Calibrated Parameter Values

\begin{tabular}{|c|c|c|}
\hline \hline Parameter & Description & Value \\
\hline$g$ & Level of good aggregate state & 1.01 \\
$b$ & Level of bad aggregate state & 0.99 \\
$h$ & Level of high idiosyncratic state & 1.064 \\
$l$ & Level of low idiosyncratic state & 0.936 \\
$\pi_{g g}$ & Persistence of good aggregate state & 0.975 \\
$\varpi_{h h}$ & Persistence of good idiosyncratic state & 0.748 \\
$\beta$ & Discount Factor & 0.980 \\
$\kappa$ & Monetary Loss per manipulated report & 3.146 \\
$\lambda(g)$ & Detection probability in good state & 0.024 \\
$\lambda(b)$ & Detection probability in bad state & 0.037 \\
$x(g)$ & Manipulation likelihood in good state & 0.060 \\
$x(b)$ & Manipulation likelihood in bad state & 0.040 \\
\hline
\end{tabular}

\subsection{Countercyclical Information}

We discuss briefly here the central mechanism in the model, since it will underlie all of the facts we discuss below. During good times, enforcement is low $(\lambda(g)<\lambda(b))$ and therefore the incentive to misreport is high $(x(g)>x(b))$; furthermore, booms are persistent $\left(\pi_{g g}>\pi_{g b}\right)$. Thus, during a boom managers will accumulate a substantial stock of negative information that they are able to hide effectively. As a result, stock prices become insensitive to upward changes in earnings, as most such reports will be rationally discounted as likely to be misrepresentations - that is, information quality is low during expansions. ${ }^{11}$ In downturns, however, intensive investigations reveal and penalize fraud, leading to widespread downward belief revisions and large downward movements in prices. Although the information asymmetry in our paper is regarding individual firm performance, the cyclical bias in financial regulatory behavior generates a systematic component in managerial reporting and subsequent fraud revelation across firms,

\footnotetext{
${ }^{11}$ This situation is different from that in van Nieuwenburgh and Veldkamp (2006) and Ilut and Saito (2018), whose models feature abundant information about aggregate productivity in booms as more firms in operation generate a higher signal-to-noise ratio for observed productivity. By contrast, the information asymmetry we study in this paper is regarding firm-level idiosyncratic state.
} 
delivering market-wide patterns in stock prices.

\subsubsection{Stock Crash Risk}

Table 2 presents the model's implications for the behavior of crash risk. We consider two definitions - the Barro and Ursua (2009) definition and the Jin and Myers (2006) COUNT variable. The first column in Table 2 shows the average percentage of firms experiencing a stock crash, defined as cumulative real return of -0.25 or lower in Barro and Ursua (2009), in good aggregate state and bad aggregate state respectively. The second and third columns show the average value of COUNT at $0.1 \%$ and $0.01 \%$ frequencies in the good and bad aggregate state. Following Jin and Myers (2006), we calculate COUNT, as the frequency of crash, based on the number of residual returns exceeding $k$ standard deviations above and below the mean, with $k$ chosen to generate frequencies of $0.01 \%$ or $0.1 \%$ in the lognormal distribution. The upside frequencies are subtracted from the downside frequencies. A high value of COUNT indicates a high frequency of crashes. In the last column, we measure crash risk using the fourth moment of stock returns about the mean scaled by squared variance.

\begin{tabular}{|c|c|c|c|c|}
\hline \multicolumn{5}{|c|}{$\begin{array}{c}\text { Table } 2 \\
\text { Crash Risk }\end{array}$} \\
\hline \hline & \% Crash & COUNT(0.1\%) & COUNT(0.01\%) & Kurtosis \\
\hline $\mathrm{a}=\mathrm{b}$ & 3.59 & 0.24 & 0.21 & 8.52 \\
$\mathrm{a}=\mathrm{g}$ & 1.22 & 0.014 & 0.06 & 3.85 \\
\hline
\end{tabular}

Our model delivers substantial countercyclical variation in crash risk; depending on the measure we get a drop in crash risk from 66 to 94 percent in the good aggregate state. We also show that the model displays strong countercyclical movements in kurtosis.

We document in the Appendix that stock market crash risks are negatively correlated with the aggregate state of the economy using the two measures above. As Figure 9 shows, overall our model delivers qualitatively similar patterns of crash risk, albeit with less variation, compared to the data - risk jumps up at the right time, although the magnitude of the jump is not as large. Part of this size differential is likely due to the fact we only have two states in our Markov process for earnings; unfortunately the learning problem becomes rapidly intractable if we add more states.

Importantly, we note that cyclical bias in regulatory oversight has implications for not only the timing but also the frequency and severity of stock crashes. Without the incentive effects, 
acyclical regulation would remove the cyclicality of stock crash without considerably altering the level of crash risk on average. As stock crash is triggered by a large amount of negative information, the protracted accumulation of aggressive manipulation in booms (specifically encouraged by loosened regulation) exacerbate both the frequency and severity of stock crashes, raising the level of crash risks on average.

\subsubsection{Countercyclical Volatility and Negative Skewness}

Table 3 shows how the cross-sectional volatility of stock returns varies with the aggregate state. While the model delivers less volatility than data overall, it matches almost perfectly the relative volatility in expansions and recessions.

\begin{tabular}{|ccccc|}
\hline \multicolumn{5}{|c|}{ Table 3} \\
Higher-Order Moments of Returns \\
\hline \hline & $\sigma(g)$ & $\sigma(b)$ & $\frac{\sigma(b)}{\sigma(g)}$ & Skew \\
\hline Model & 0.03 & 0.04 & 1.53 & -0.062 \\
Data & 0.1 & 0.14 & 1.39 & -0.139 \\
\hline
\end{tabular}

Gradual booms and sudden crashes in the financial markets have been well documented: stock price declines are sharper than any boom of equal magnitude (e.g., Veldkamp, 2005). As a measure of this asymmetry between booms and crashes, skewness is negative in both our model and the data. The size of skewness is only half as large as found in the data; as with crash risk, this shortfall is at least partially attributable to the two-state Markov process for earnings.

\subsection{Time Irreversibility}

In this section we consider more generally the asymmetric dynamics present in stock returns and how our model fares at reproducing it. Specifically, following Ramsey and Rothman (1996), we look at time reversibility, which we define here as in that paper.

Definition 1 A random variable $X$ is time-reversible if

$$
E\left[X_{t}^{i} \cdot X_{t-k}^{j}\right]=E\left[X_{t}^{j} \cdot X_{t-k}^{i}\right]
$$

holds $\forall i, j, k$. The superscripts denote powers and the subscripts denote time. 
Table 4 shows the pattern of coefficients for the model and the data. We use $i=2, j=1$, and $k \in\{1,2,3,4\}$. The TR-test from Ramsey and Rothman (1996) strongly rejects the presence of time reversibility in both the data and model time series for stock prices (the portmanteau test statistics are 13.767 and 18.686 in the data and the model, respectively, which are significant at 5 percent and 1 percent). The model fits the general sign pattern well, although the magnitudes are smaller.

\begin{tabular}{|ccccc|}
\hline \multicolumn{5}{|c|}{ Table 4 } \\
\hline \multicolumn{5}{|c|}{ Test of Time-Reversibility } \\
\hline \hline$k$ & 1 & 2 & 3 & 4 \\
\hline Data & 0.046 & -0.606 & -3.022 & -1.981 \\
Model & 0.001 & -2.030 & -3.057 & -2.042 \\
\hline
\end{tabular}

\subsection{Discussion: Key Drivers of Model Predictions}

This subsection discusses which of the model's features are necessary for its key results. In substance, there are three essential features in the model. First and foremost, there is cyclical bias in regulatory oversight, which encourages frauds in booms and reveals them in recessions. Second, revelation of manipulation imposes adverse consequences on firms. These two elements deliver the asymmetries in stock returns: In bad times, strengthened regulation leads to waves of frauds to be revealed and penalized, causing stocks to plummet; in good times, lack of information revelation renders stock fluctuations mild. In addition, investors' Bayesian learning of manipulation also plays an important role: rational investors are aware of but cannot perfectly see through manipulation; therefore, the noise in financial information mitigates stock responses in booms and actual detection of fraud during downturns can lead to downward revisions in beliefs about firms' prospects, exacerbating the asymmetric pattern. We note that we abstract away from risk aversion to simplify our analysis, and it is natural to envision that with a state-dependent stochastic discount factor, the large monetary losses investors incur for fraud detection during downturns (exactly when investors' consumption growth is low) can translate into a higher equity premium demanded by investors. Now we discuss each of the three key elements in detail below.

\section{Cyclical bias in regulation and fraud}

As we discuss in detail in Section 2, we provide new evidence that the intensity of financial regulatory oversight varies systematically depending on the aggregate state of the economy, 
leaving more discretion to corporate managers in booms than during downturns. As a result, incentives to maximize financial gains by artificially overstating firm performance are stronger in booms when regulatory actions are less likely. There has been empirical evidence that a boom encourages and conceals misrepresentation by firms, which are then revealed by the ensuing recession (e.g., Povel, Singh, and Winton, 2007; Brunnermeier et al., 2009; Cohen and Zarowin, 2012; McDonnell, 2013).

\section{Negative consequences of manipulation}

In the model, revelation of manipulation imposes a large amount of financial losses on investors, which generates sharp declines in returns. This model feature is intended to capture the substantial financial cost of manipulation that investors bear in practice, and it is also necessary in closing the model in a consistent manner. The Securities and Exchange Commission (SEC) enforcement actions and restatement announcements are associated with drastic market reactions and negative impact on firms' future prospects (e.g., stock returns on average fall by about $10 \%$ around earnings restatements in the data). The SEC has collected over $\$ 30$ billion penalties in fraud cases since 2002, and the amount of settlement fines has been growing over time. The loss of confidence in corporate financial reporting could also hurt business and investment opportunities. Furthermore, the reduced availability and higher cost of capital may force firms to forgo investment and accelerate layoffs. This financial cost also captures the adverse consequences of manipulation on firms' future productivity as manipulation is often done by taking suboptimal economic decisions: managers may engage in activities that boost current earnings at the expense of future benefits, such as forsaking profitable investment and postponing R\&D and capital spending plans. ${ }^{12}$ Karpoff, Lee, and Martin (2008) estimate that for each dollar of misreported earnings, a firm loses $\$ 4.08$ when manipulation is revealed.

\section{Investors' Bayesian learning}

One important and novel feature of the model is the Bayesian updating procedure that investors follow to extract information and price the assets. With each new report from the manager, rational investors form their belief about historical performance (because penalties also depend on previous manipulation), make inferences about the current outcome, and predict future earnings. It is similar to Kalman smoothing problems, yet with Bayesian updating aspects. In the case with stochastic investigation, investors need to keep track of the entire

\footnotetext{
${ }^{12}$ Graham et al. [2005] document that $78 \%$ of executives in their survey admit to sacrificing long-term value to maintain predictability in earnings.
} 
history of reports and keep updating on everything that happened in the infinite past. This learning process creates an additional channel through which cyclical regulation dampens stock responses in good times (less learning) and generates large downward movements in bad times (belief revision).

\section{Conclusion}

We construct new indexes of financial regulatory intensity (FRI) and find patterns resembling a "regulatory sine curve": the intensity of financial regulatory intensity is negatively associated with the aggregate economic conditions. We then develop and calibrate a model that is meant to capture a simple piece of intuition about the effect of cyclical regulatory policies on stock markets: negative information hidden by corporate executives is more likely to be flushed out through investigations when the economy is falling as opposed to rising. Critically, this dynamic feeds on itself, potentially amplifying moderate adverse shocks into more serious financial strains. This mechanism can help shed light on a variety of stylized facts and, in particular, stock crash risk. Our model indicates that the dual role of regulatory oversight in both deterring manipulation and revealing hidden negative information has considerable implications for asset pricing, and their timing is important for crash risks in the stock market. History suggests that firms do not have incentives to build resilience when times are good. Given the risks to the financial system and economy from the adverse amplifying mechanism, independent regulatory bodies should serve as a counterweight and be proactive, not reactive, preventing the downward spiral in the financial markets during periods of stress.

\section{References}

[1] Albuquerque, R.A., Wang, N., (2008). "Agency conflicts, investment, and asset pricing." Journal of Finance 63(1), 1-40.

[2] Baker, S. R., Bloom, N. Davis, S. J., (2016). "Measuring Economic Policy Uncertainty." Quarterly Journal of Economics 131, 1593-1636.

[3] Barro, R.J., Ursua, J.F., (2009). "Stock-market crashes and depressions." NBER Working Paper No. 14760.

[4] Berger, A. N., Kyle, M., Scalise, J. (2001). "Did U.S. bank supervisors get tougher during the credit crunch? Did they easier during the banking boom? Did it matter to bank lend- 
ing?" In Frederick Mishkin, Ed. Prudential Supervision: What Works and What Doesn't? Chicago, IL: University of Chicago Press.

[5] Bernanke, B., Gertler, M., (1989). "Agency costs, net worth, and business fluctuations." American Economic Review 79(1), 14-31.

[6] Bertomeu, J., Magee, R.P., (2011). "From low-quality reporting to financial crises: politics of disclosure regulation along the economic cycle." Journal of Accounting and Economics 52(2), 209-227.

[7] Brunnermeier, M., Crocket, A., Goodhart, C., Persaud, A.D., Shin, H, (2009). "The fundamental principles of financial regulation." Geneva London: International Center for Monetary and Banking Studies Centre for Economic Policy Research.

[8] Chen, K., Zha, T., (2015). "Assessing the macroeconomic impact of bank intermediation shocks: a structural approach." Federal Reserve Bank of Atlanta Working Paper.

[9] Cohen, D., Zarowin, P., (2007). "Earnings management over the business cycle." New York University Working Paper.

[10] Feroz, E.H., Park, K., Pastena, V.S., (1991). "The financial and market effects of the SEC's accounting and auditing enforcement releases." Journal of Accounting Research 29, 107-142.

[11] Greenwood, J., Sanchez, J.M., Wang, C., (2010). "Financing development: the role of information costs." American Economic Review 100, 1875-91.

[12] Hinich, M.J., (1982). "Testing for gaussianity and linearity of a stationary time series." Journal of Time Series Analysis 3, 169-176.

[13] Hinich, M.J., Rothman, P., (1998). "Frequency-domain test of time reversibility." Macroeconomic Dynamics 2(1), 72-88.

[14] Ilut, C.L., Saito, H., (2018). "Learning, confidence, and business cycles." NBER Working Paper No. 22958.

[15] Jin, L., Myers, S.C., (2006). " $R^{2}$ around the world: new theory and new tests." Journal of Financial Economics 79(2), 257-292.

[16] Karpoff, J.M., Lee, D.S., Martin, G.S., (2008). "The cost to firms of cooking the books." Journal of Financial and Quantitative Analysis 43(3), 581-612.

[17] Kiyotaki, N., Moore, J., (1997). "Credit cycles." Journal of Political Economy 105(2), 211-248. 
[18] Laeven, L., Majinoni, G., (2002). "Loan-loss provisioning in an economic slowdown: Too much, Too late?" World Bank Working Paper.

[19] McDonnell, B., (2013). "Dampening financial regulatory cycles," Florida Law Review 65, 1597-1639.

[20] Peltzman, S., (1976). "Toward a more general theory of regulation." Journal of Law and Economics 19(2), 211-240.

[21] Povel, P., Singh, R., Winton, A., (2007). "Booms, busts, and fraud." Review of Financial Studies 20(4), 1219-1254.

[22] Ramsey, J.B., Rothman, P., (1996). "Time irreversibility and business cycle asymmetry." Journal of Money, Credit, and Banking 28(1), 1-21.

[23] Ruckes, M., (2004). "Bank competition and credit standards." Review of Financial Studies 17(4), 1073-1102.

[24] Stigler, G.J., (1971), "The theory of economic regulation." Bell Journal of Economics and Management Science 2(1), 3-21.

[25] Sun, B., (2014). "Asset returns under periodic revelations of earnings management." International Economic Review 55(1), 255-282.

[26] Syron, R., (1991). "Are we experiencing a credit crunch?" New England Economic Review. July-August 3-10.

[27] Terry, S.J. (2018). "The macro impact of short-termism." Manuscript, Boston University.

[28] van Nieuwerburgh, S., Veldkamp, L., (2006). "Learning asymmetries in real business cycles." Journal of Monetary Economics 53(4), 753-772.

[29] Veldkamp, L., (2005). "Slow boom, sudden crash." Journal of Economic Theory 124, 230257.

[30] Wang, T.Y., Winton, A., Yu, X., (2010). "Corporate fraud and business conditions: evidence from IPOs." Journal of Finance 65(6), 2255-2292.

[31] Yu, F., Yu, X., (2011). "Corporate lobbying and fraud detection." Journal of Financial and Quantitative Analysis 46(6), 1865-1891. 
Figure 1: Financial Regulation Index (Annual)

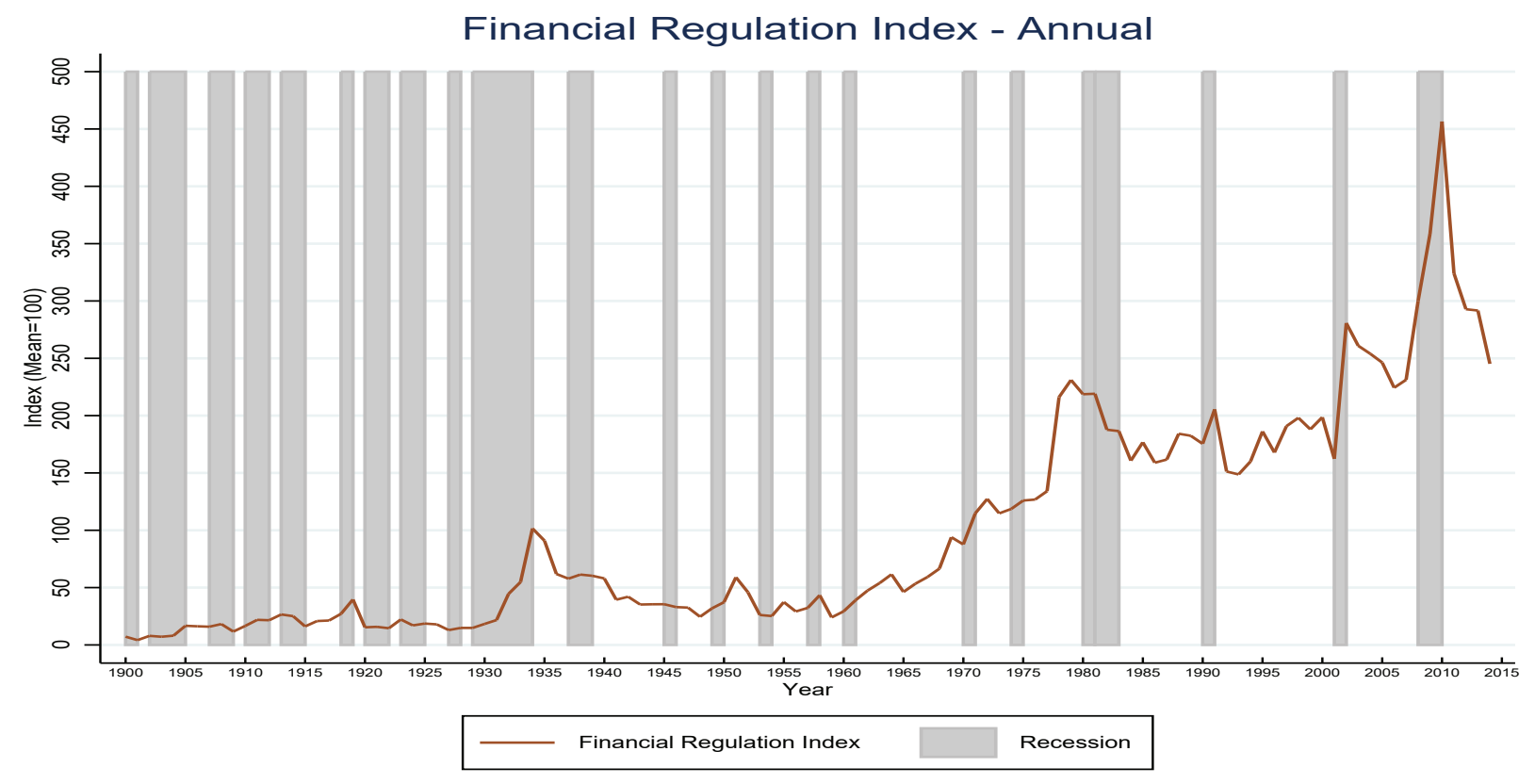

Figure 2: Financial Regulation Indexes and GDP Growth

Panel A: FRI

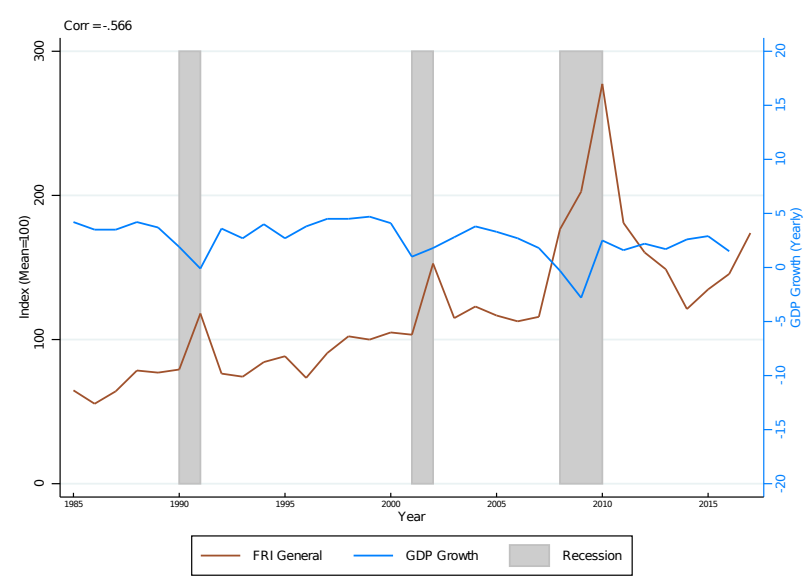

Panel B: subindex

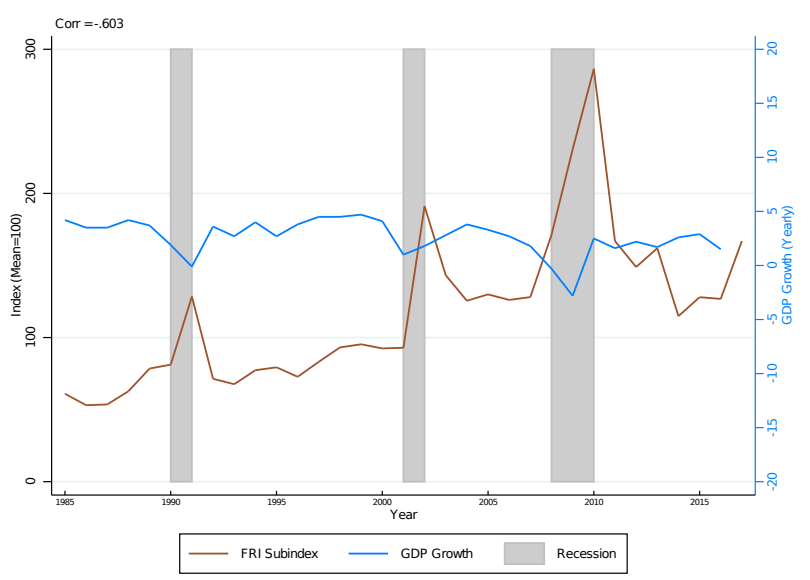


Figure 3: Impulse Responses to a Negative IP Shock

Panel A: FRI
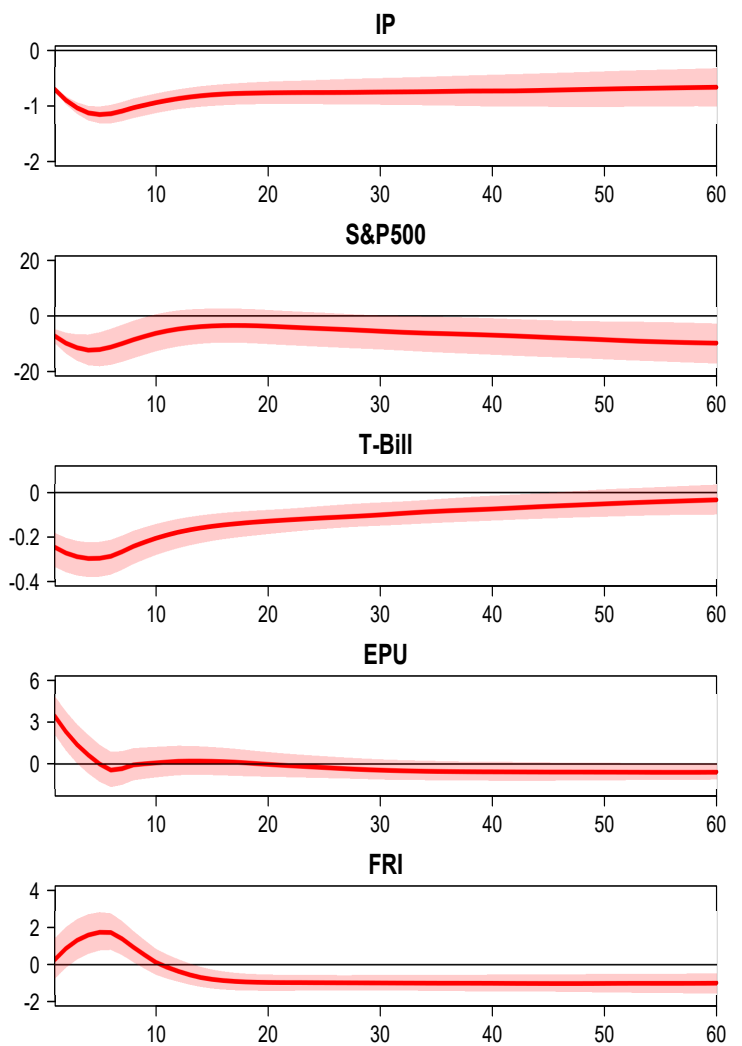

Panel B: Sub-FRI
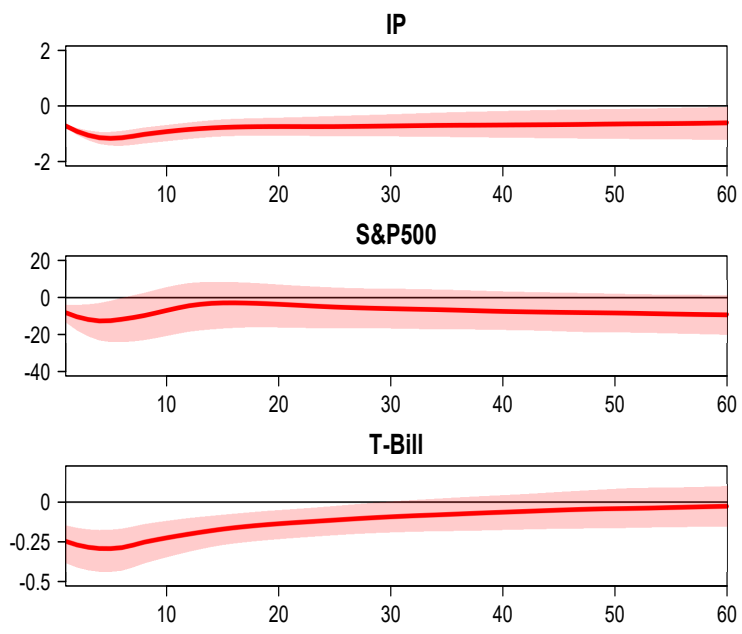

EPU

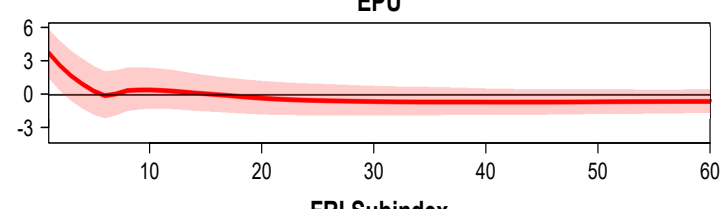

FRI Subindex

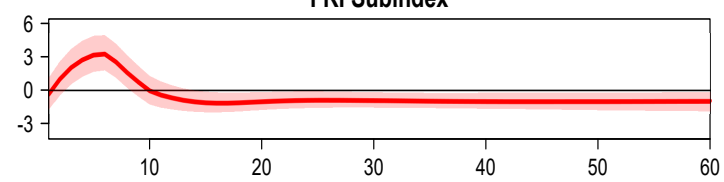


Figure 4: Impulse Responses to a Positive FRI Shock
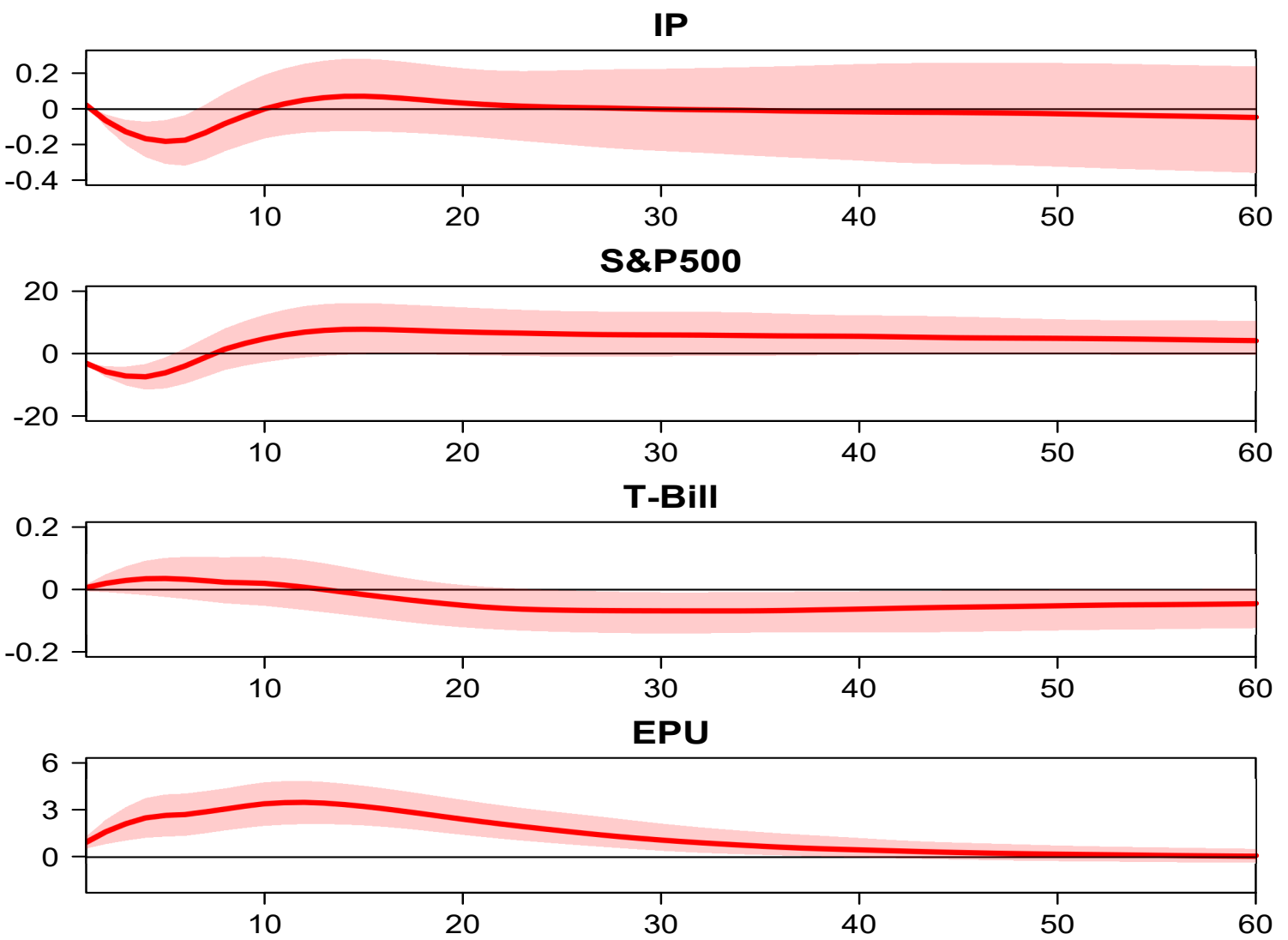

FRI

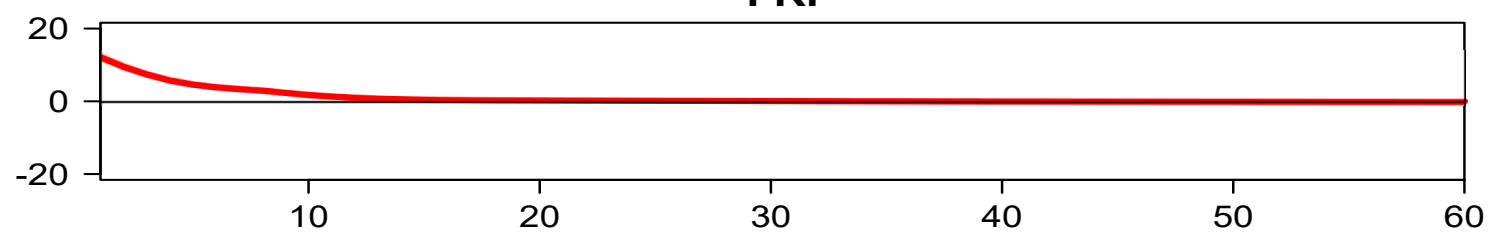


Figure 5: Expected Penalty Function

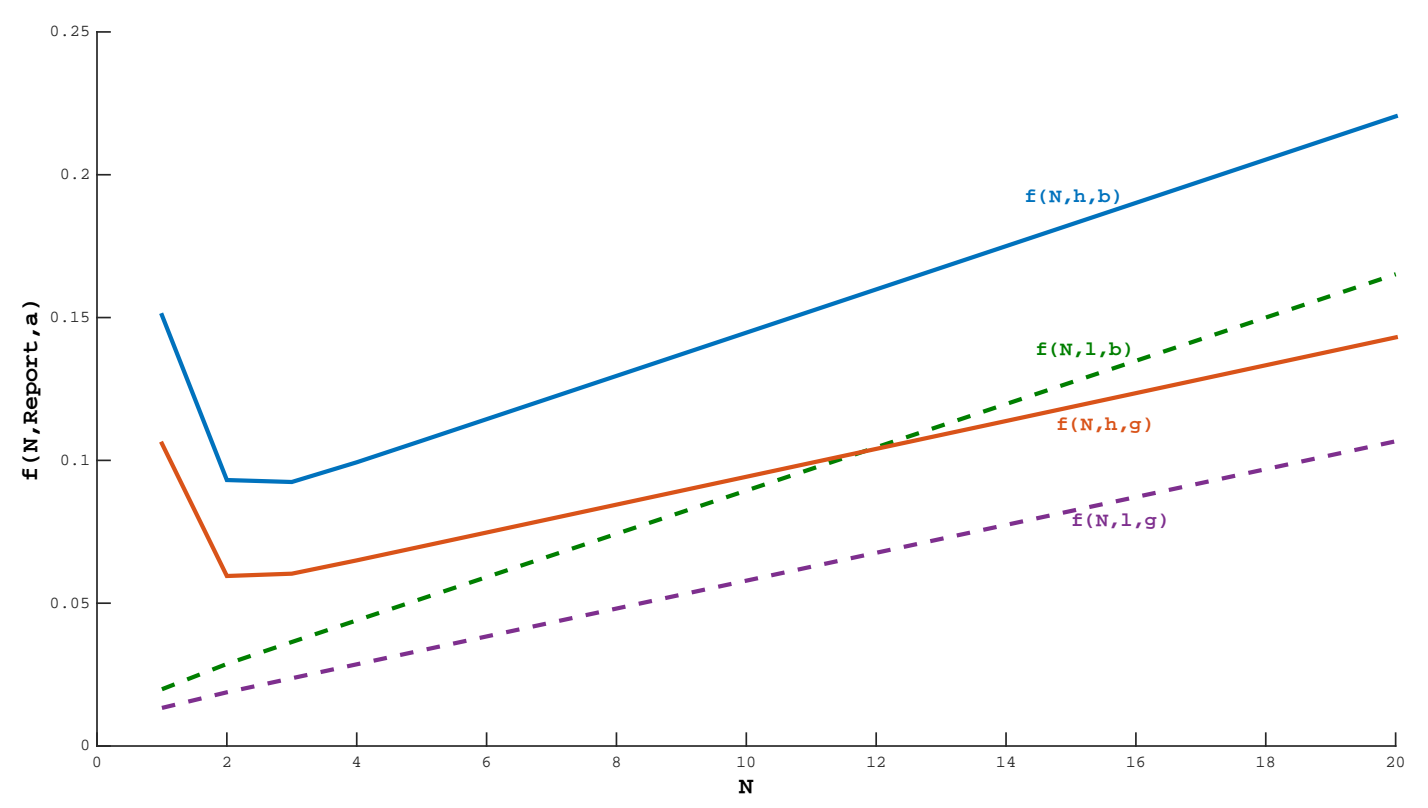

Figure 6: Pricing Function

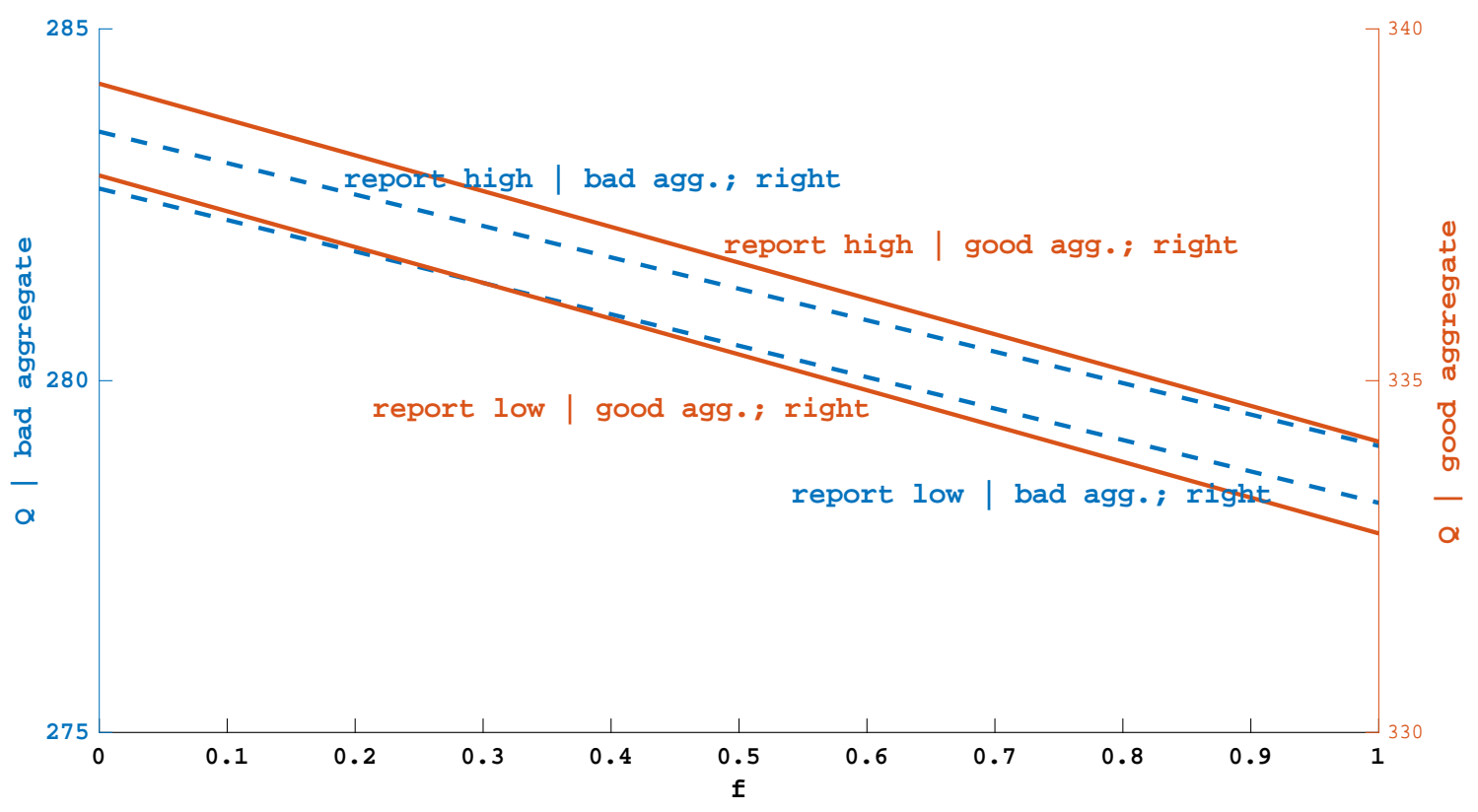


Figure 7: Pricing Function

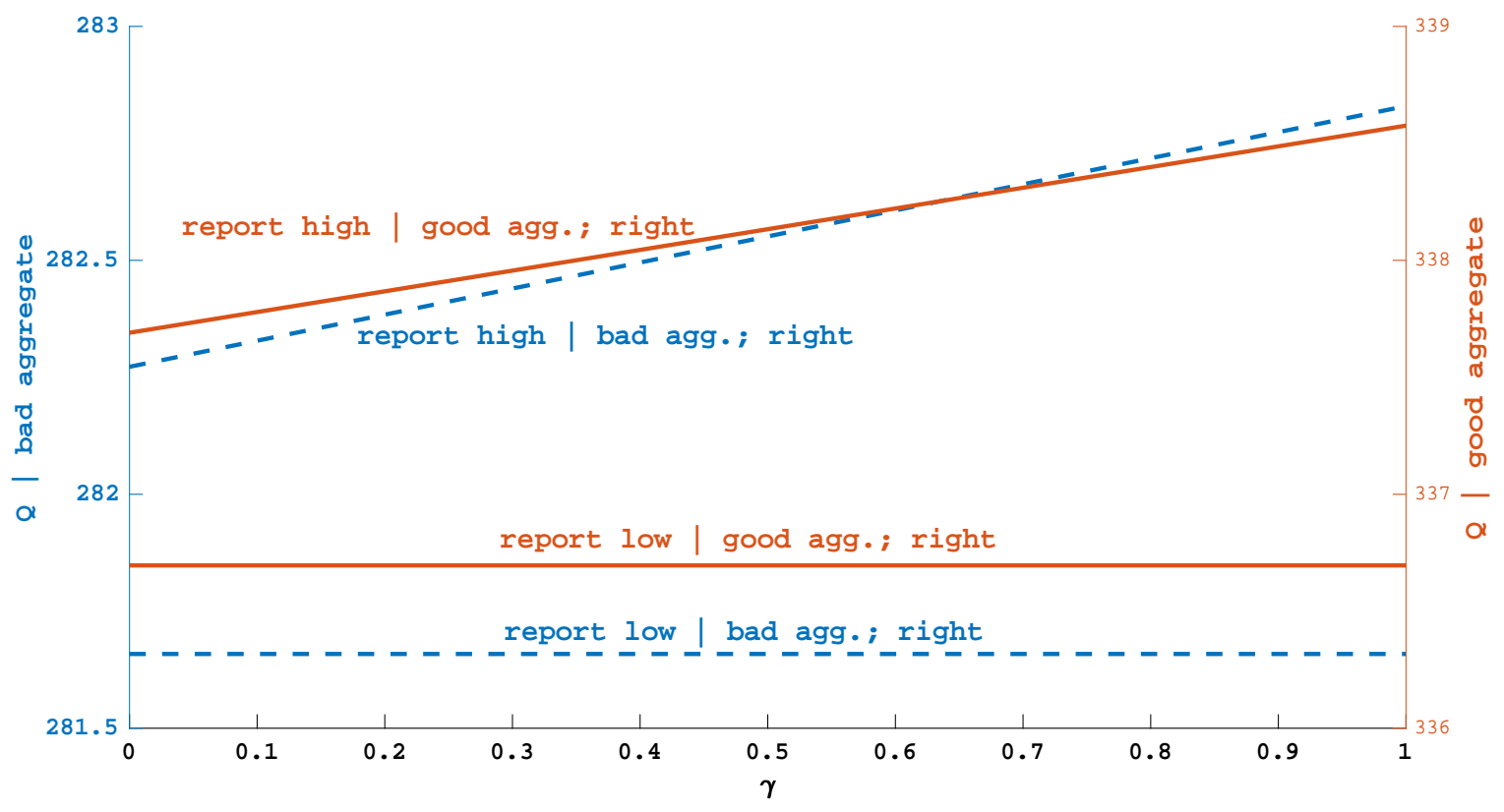

Figure 8: Pricing Function

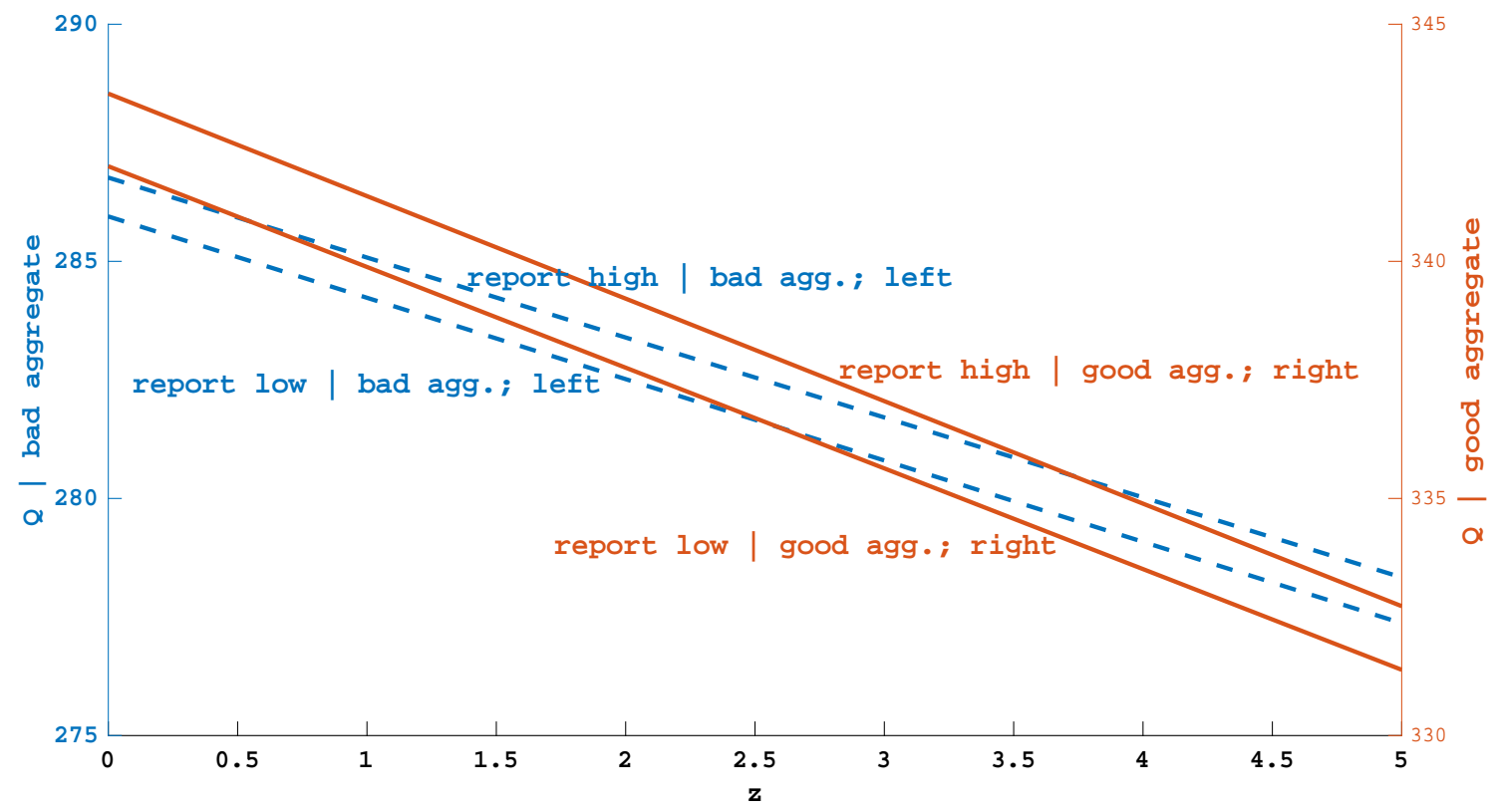


Figure 9: Barro-Ursua Crash Risk

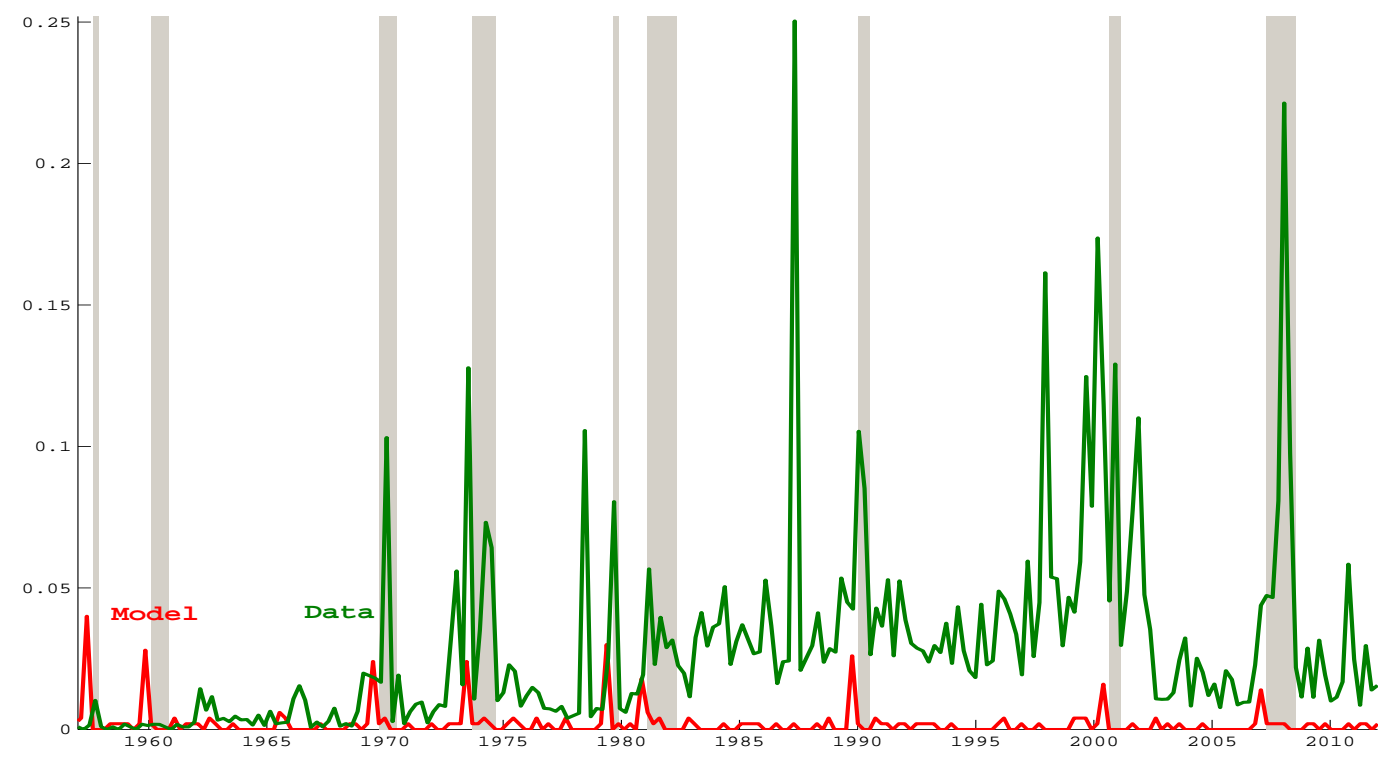




\section{Online Appendix}

\section{A Financial regulation index construction}

The financial regulation index reflects text-search results for the newsstand edition of three major newspapers: New York Times, Wall Street Journal, and Washington Post. We use the ProQuest Newsstand database to search the electronic archives of each newspaper from January 1900 to January 2016 for terms related to monetary policy uncertainty. In particular, the search identifies articles containing the triple of ((i) "regulation" or "regulatory," (ii) "financial" or "finance," and (iii) one or more of the following terms: "congress," "federal reserve/fed," "SEC/ Security and Exchange Commission," "OCC/Office of the Comptroller of the Currency," "FDIC/Federal Deposit Insurance Corporation," "stock exchange". Based on these search criteria, we count in each newspaper how many articles contained the search terms above each day.

To account for changing volume of newspapers over time, we normalize as follows. First, we divide, for each newspaper, in every inter-meeting period, the raw count of articles related to financial regulation (FR) by the total article count. For each newspaper $i$ in period $t$, we calculate the share of articles containing financial regulation terms as

$$
n(i, t)=\frac{\# \text { FR_articles }(i, t)}{\text { \#total_articles }(i, t)} .
$$

We then normalize the share of articles so that, for each newspaper, the resulting series has a standard error of one over the sample period. This normalization controls for the possibility that different newspapers mention financial regulation with different frequencies over time. That is, we denote the normalized share of articles using

$$
n n(i, t)=\frac{n(i, t)}{\operatorname{stdev}(n(i, 1985: 2015))} .
$$

Finally, we sum the $n n(i)$ series across newspapers and scale them so that the average value is 100 over the sample period. The scaling produces our financial regulation index (FRI):

$$
F R I(t)=\left[\frac{\sum_{i} n n(t)}{\operatorname{avg}\left(\sum_{i} n n(1985: 2015)\right)}\right] \times 100 .
$$

A human reading of a sample of the articles suggests that the news-based approach used to construct the index can provide a reasonable indicator of financial regulation. Newspapers typically cite financial regulation in one of the following cases: 
- Newspaper articles describe regulatory structure and policy. For example, "Under the Treasury's proposal, the bank supervisory powers of the Fed and the Federal Deposit Insurance Corporation would be taken over by a single Federal Banking Commission. The commission would also take over the Treasury's two bank monitoring arms, the Office of the Comptroller of the Currency and the Office of Thrift Supervision." (January 25, 1994, New York Times)

- Newspaper articles discuss a specific regulatory action. For example, "The OCC and FDIC, which regulate Citigroup's Citibank and Banamex USA subsidiaries, demanded the correction of deficiencies in its anti-money-laundering compliance." (March 27, 2013, Wall Street Journal)

- Newspaper articles analyze current debate and potential movements in regulatory policy. For example, "In the White House's efforts to gain traction on its proposal to revamp financial-market supervision, a key flashpoint has been how much regulatory power should be centralized in the Fed and how much should be shared by a council of regulators". (October 02, 2009, Wall Street Journal) "The Bush Administration is preparing to recommend the creation of a "super regulator" of banks, savings associations and other financial services, in a sweeping overhaul of the complex regulatory system." (January 07, 1991, New York Times)

- Newspaper comment on issues with regulatory restrictions. For example, "Dodd-Frank restrictions on the Federal Reserve's powers to act as lender-of-last-resort, coupled with restrictions on federal guarantees for bank deposits and money-market funds, pose a threat to U.S. and global financial stability. In addition, the FDIC cannot expand guarantees to bank depositors without congressional approval, and the Treasury can't do the same to money-market funds without new legislative authority. These changes could make it difficult for the Fed and other regulatory bodies to act effectively in the next crisis." (March 02, 2015, Wall Street Journal)

\section{B Additional evidence on cyclical regulatory bias}

In this section we gather additional evidence on the time-series pattern of regulatory behavior specifically targeted at managerial manipulation and show that the intensity of regulatory actions peaked during NBER recessions over the recent business cycles. There does not exist a long time series, besides our new indexes, that we can exploit here, so we assemble a large number of sources that indicate how regulators have responded to downturns. The evidence gathered in this section sheds some additional, albeit anecdotal, light on the plausibility of the cyclical bias in financial regulatory behavior. 
Our first piece of evidence is the percentage of firms that received a Securities and Exchange Commission (SEC) comment letter. The SEC issues comment letters to registrants if the staff has questions or concerns related to a disclosure filing or if the staff believes the filing is incomplete or requires improvement. These comment letters may involve requests for additional information, revised disclosures, or additional disclosures of firm information. If the concerns in the comment letters are not resolved, formal investigations and enforcement actions will follow. As shown in Figure 10, the number of comment letters issued peaked during the Great Recession; unfortunately, since the SEC only began releasing this information (via the EDGAR database) in 2005, we cannot examine whether this particular measure similarly peaked during other recessions.

Another piece of evidence we use is the number of litigation cases related to financial information manipulation, using Audit Analytic's Litigation Database on all federal securities class action claims, SEC actions, and material federal civil legislation. Figure 11 shows that the percentage of firms subject to litigation related to performance manipulation rose during the recession of 2001, remained high (possibly due to the Sarbanes-Oxley Act of 2002), and then peaked again during the Great Recession; the correlation with an indicator of NBER recessions is 0.40 , showing that recession periods are associated with more regulatory actions. Similarly, in the plot we include the S\&P500 index price; the correlation with this index is -0.51 .

Figure 12 is borrowed from Bertomeu and Magee (2011). The Financial Accounting Standards Board (FASB) is a private standards-setting organization that chooses the rules for accounting by nongovernmental entities; the decisions of FASB are officially recognized as authoritative by the SEC. The figure documents that the number of Statements of Financial Accounting Standards (SFAS) is significantly higher during NBER recessions compared to expansions; this pattern also holds for the length of these statements (an intensive margin) and is somewhat stronger in fact.

We also obtained data from the General Accounting Office (GAO) that documents the number of enforcement actions undertaken by the SEC during the period 1977-1984. Figure 13 plots the number of actions per staff member, adjusted for the length of time that a typical action lags behind the beginning of an investigation (1.64 years). It is easy to see that the "activity" of SEC staff members bottomed out at the onset of the 1979 recession and rose during the subsequent long downturn.

The evidence gathered in this section hints at a cyclical bias in financial regulatory actions targeted at information manipulation, with the caveat that (i) the data series only cover the recent years and (ii) only fraud detection, not all investigations, is observable in the data series (with the exception of the SEC comment letters). The shortcomings of the existing data prompt us to conduct the textual analysis based on newspaper coverage in Section 2. 
Figure 10: Comment Letters from SEC

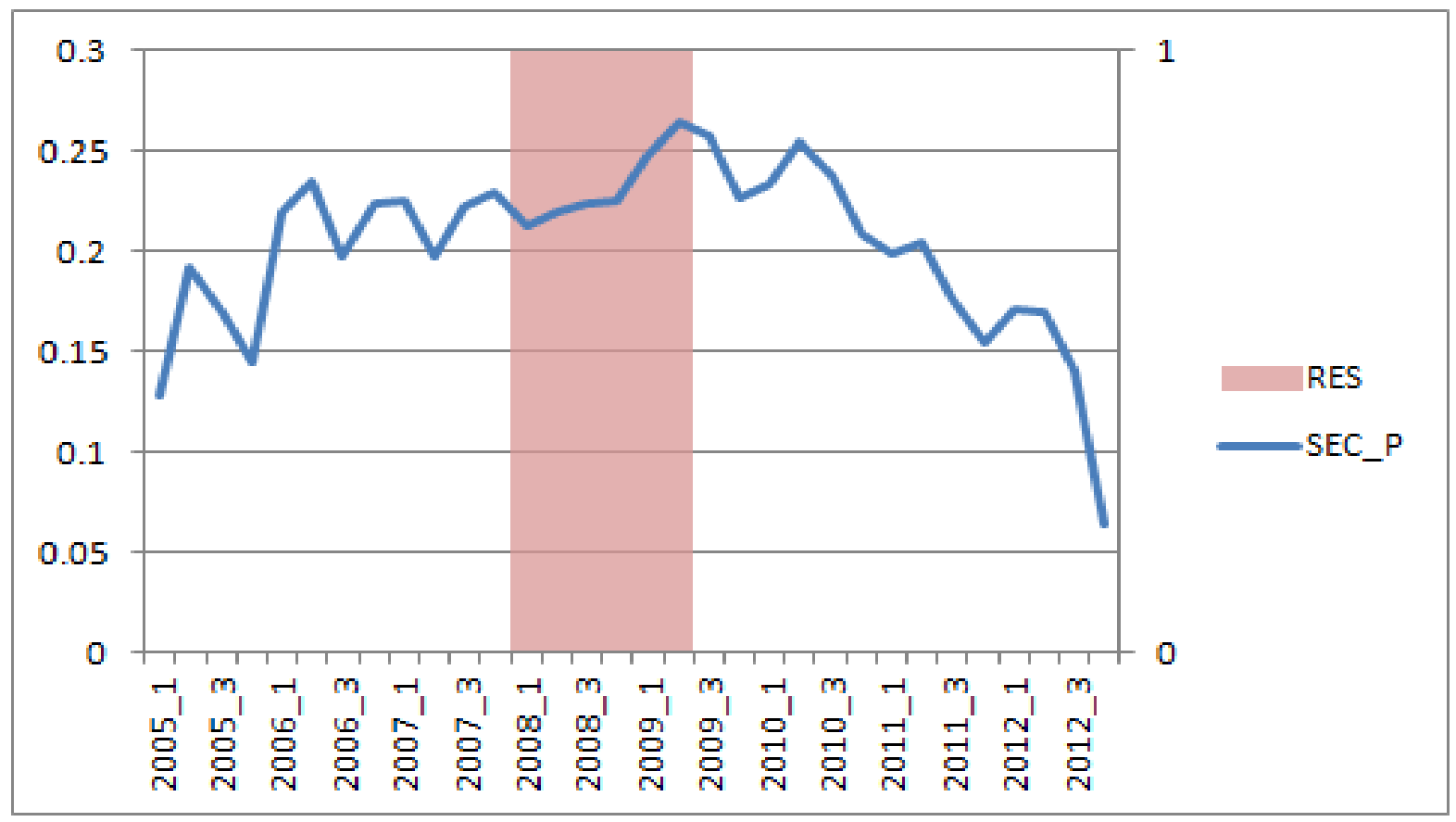

Figure 11: Legal Actions by the SEC

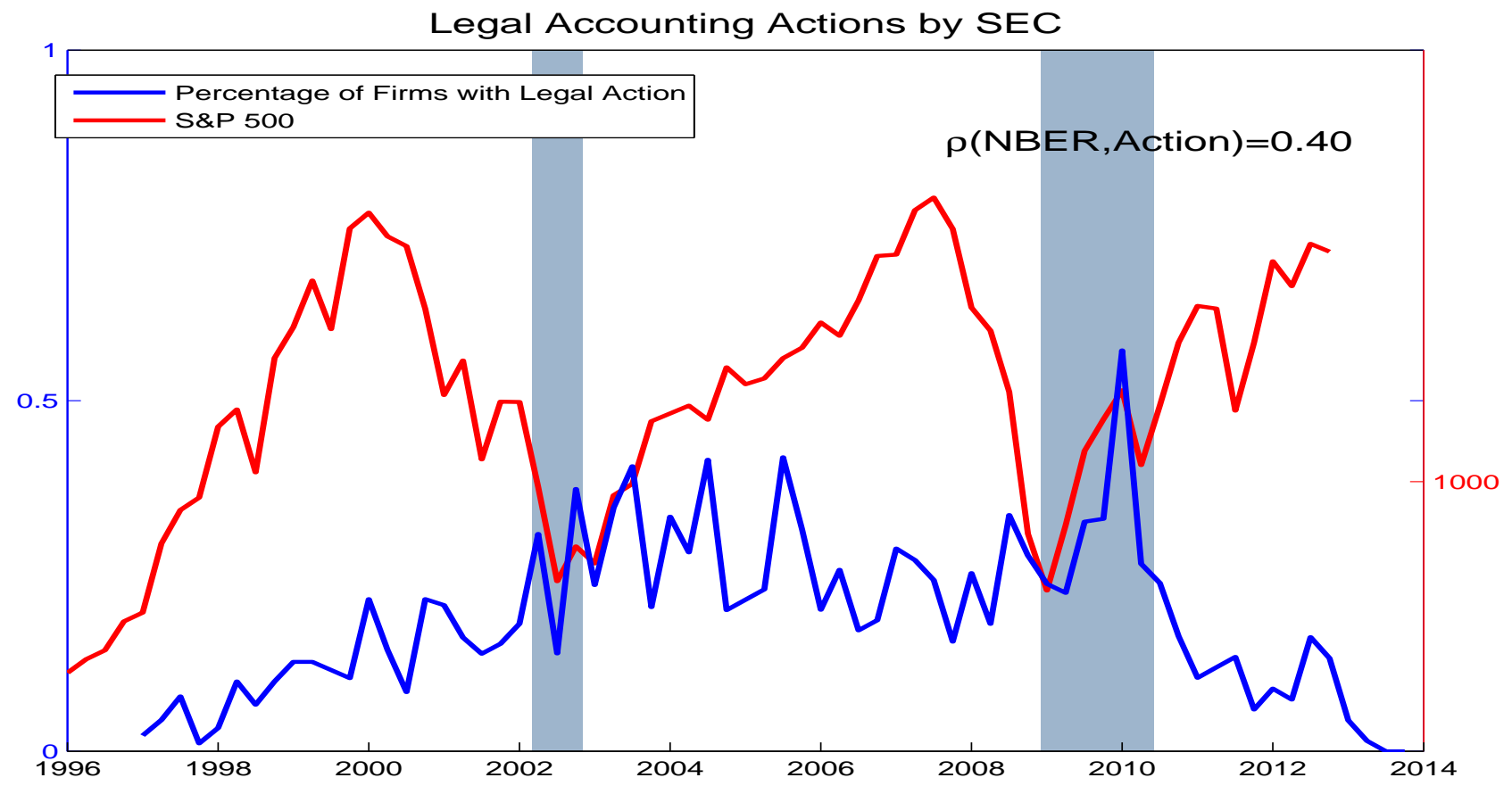


Figure 12: FASB Actions

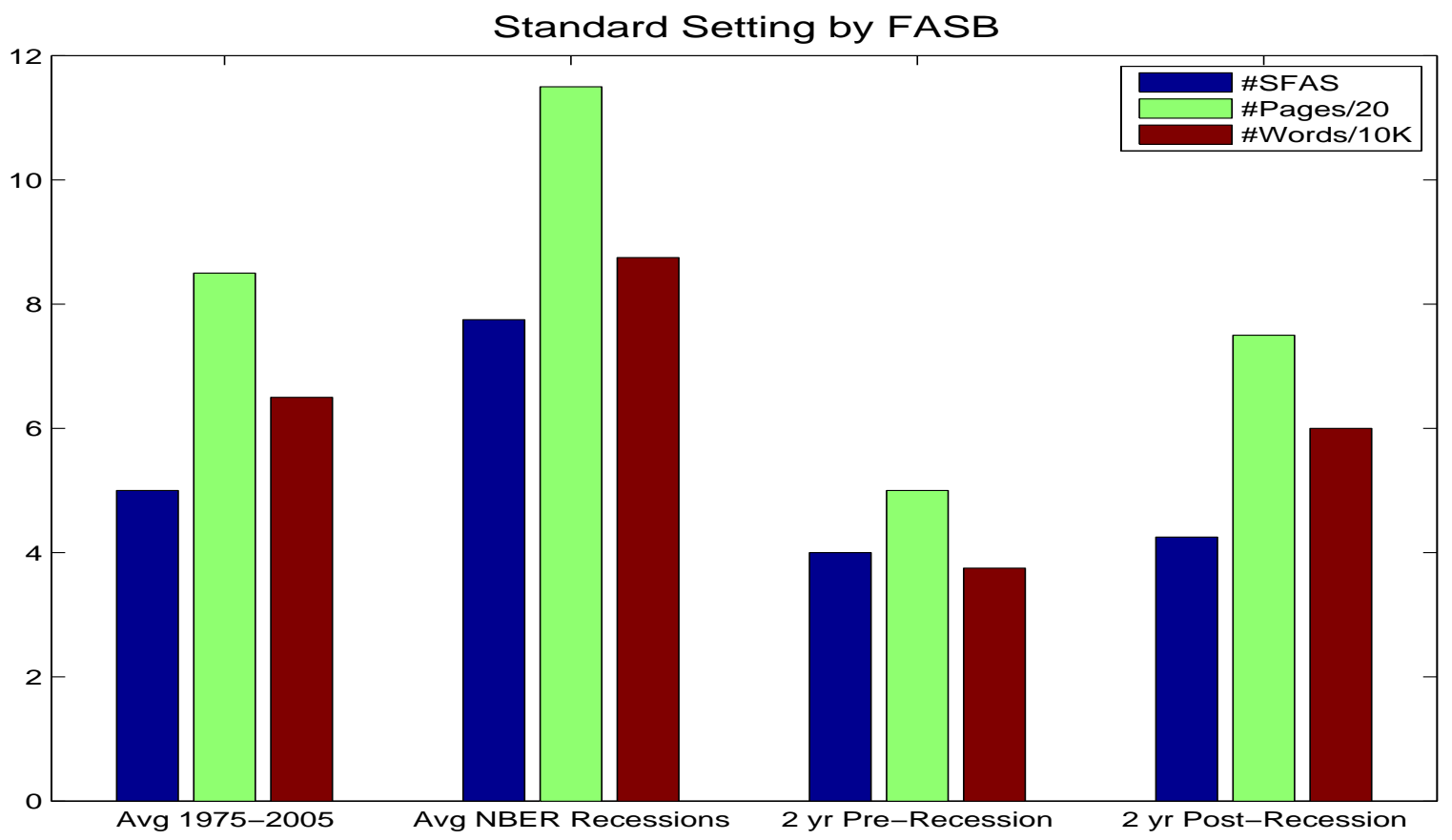

Figure 13: Enforcement Activity over the Cycle

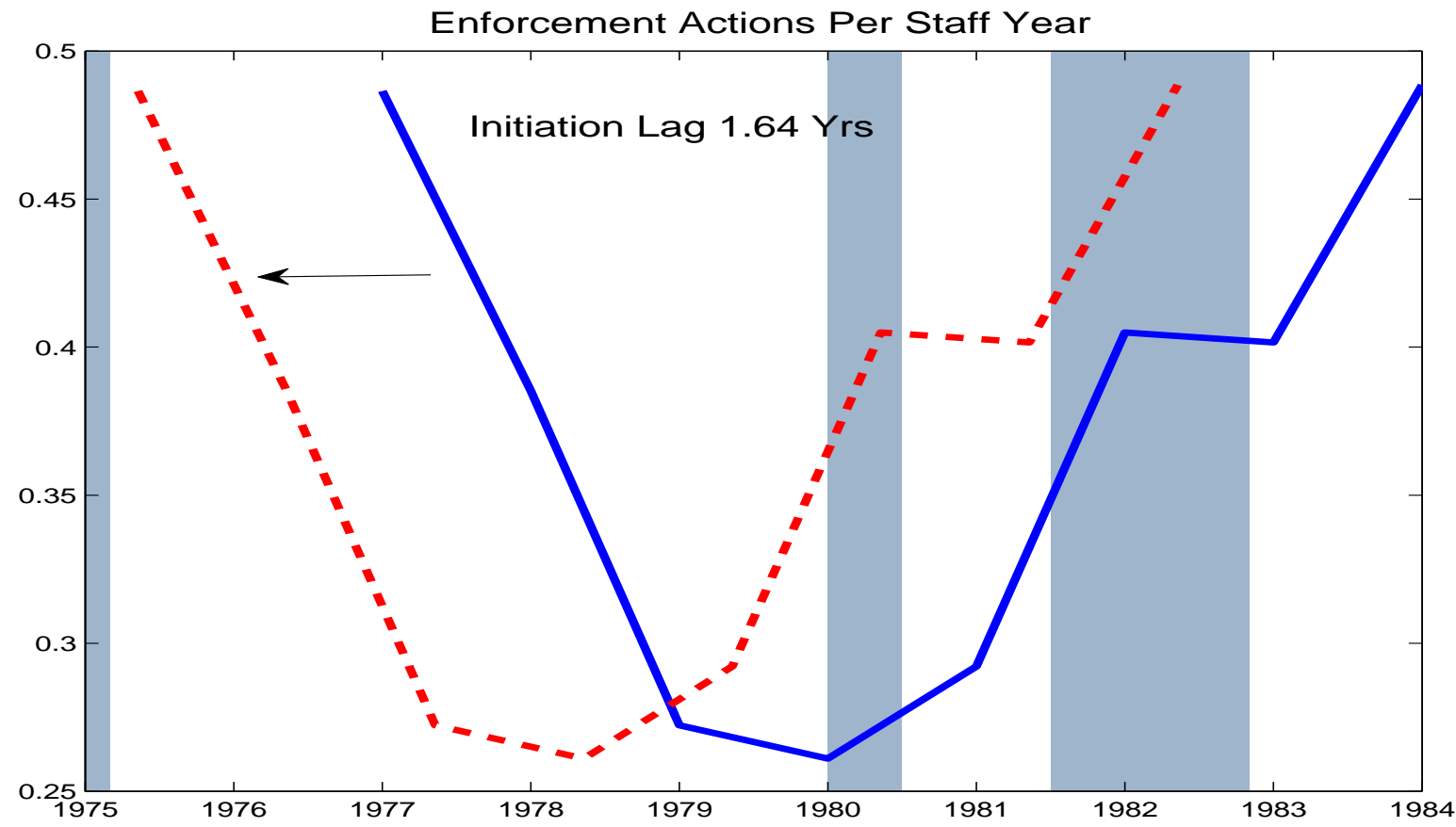




\section{Robustness: alternative Cholesky ordering}

Figure 14: Impulse responses to IP shocks, Cholesky identification with different orderings

Panel A: FRI ordered 2nd
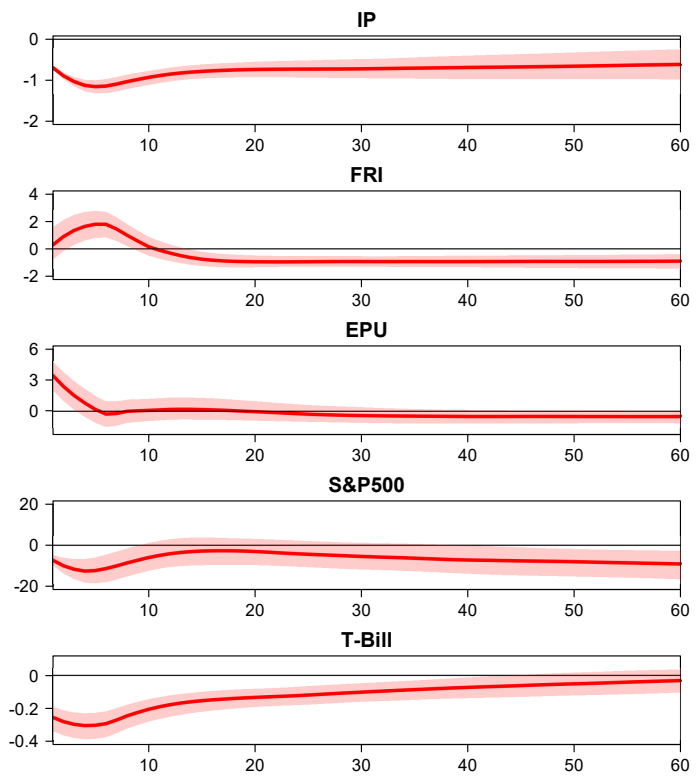

Panel C: FRI ordered 4th
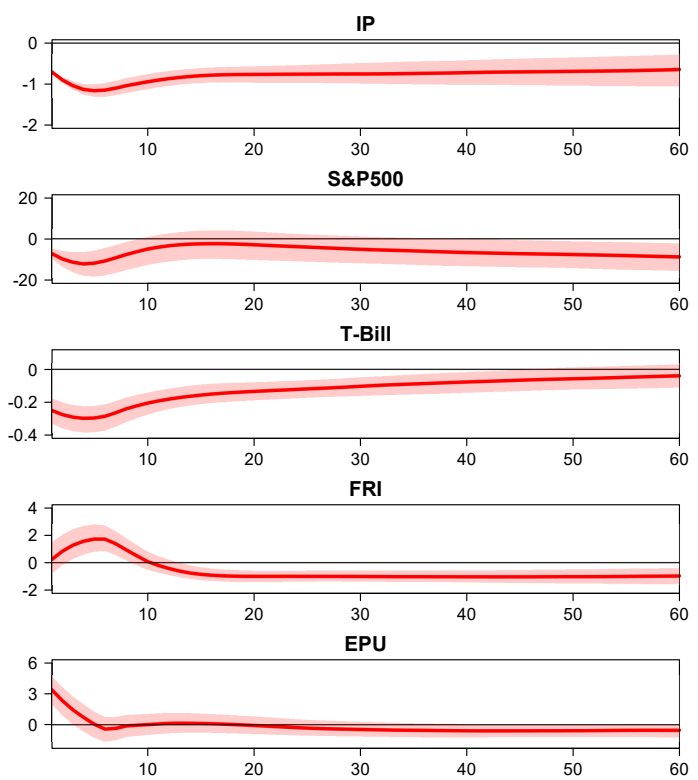

Panel B: FRI ordered 3rd
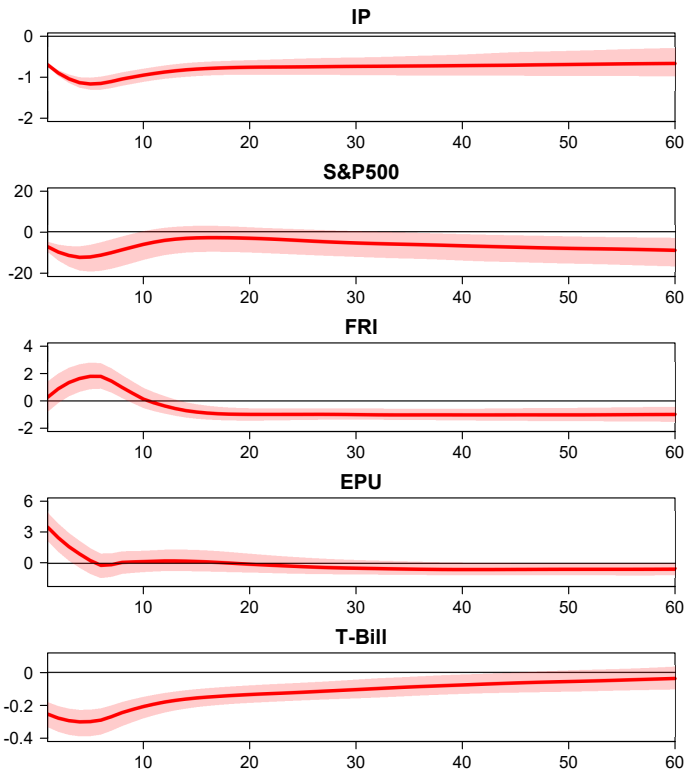

Panel C: FRI ordered 5th
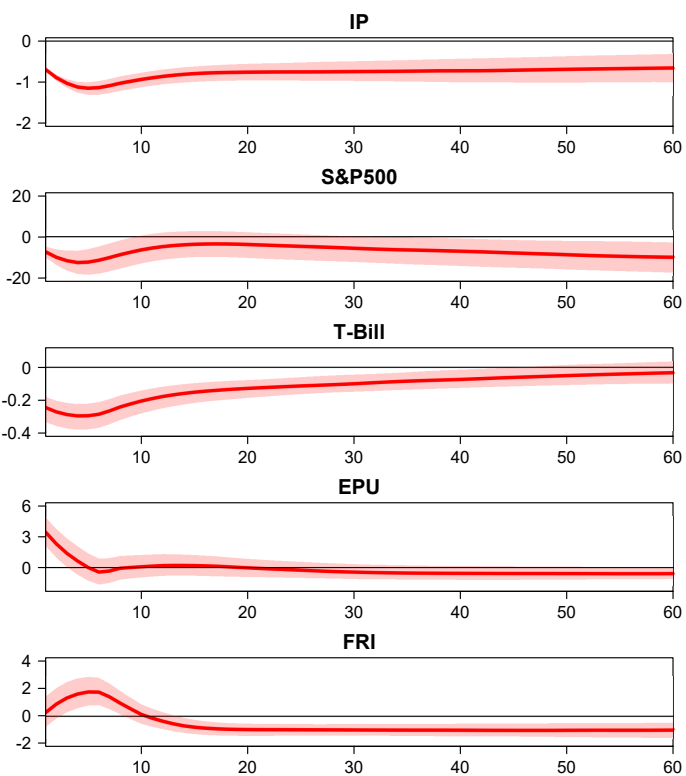
Figure 15: Impulse responses to FRI shocks, Cholesky identification with different orderings

Panel A: FRI ordered 1st
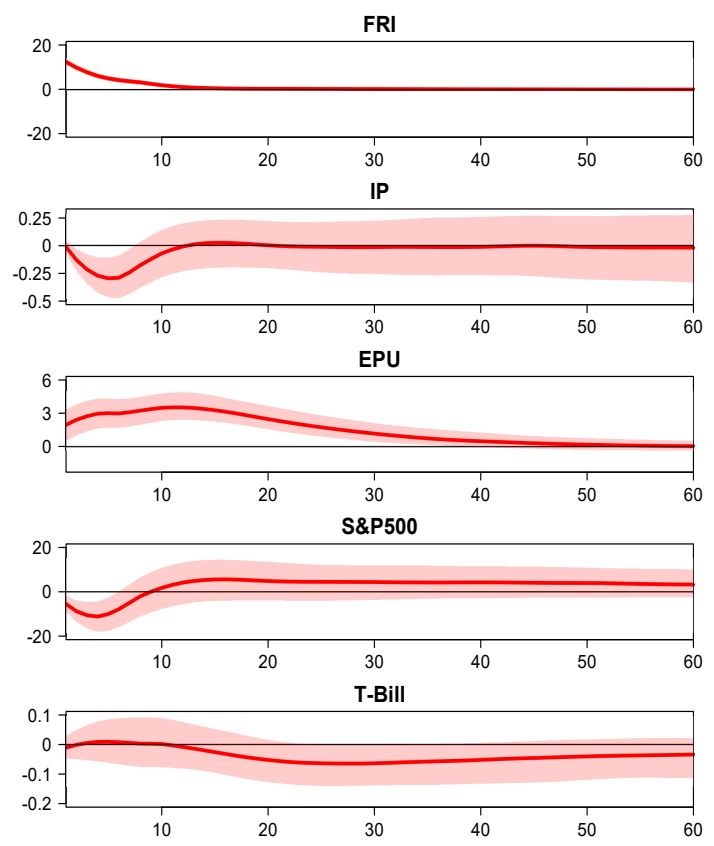

Panel C: FRI ordered 3rd
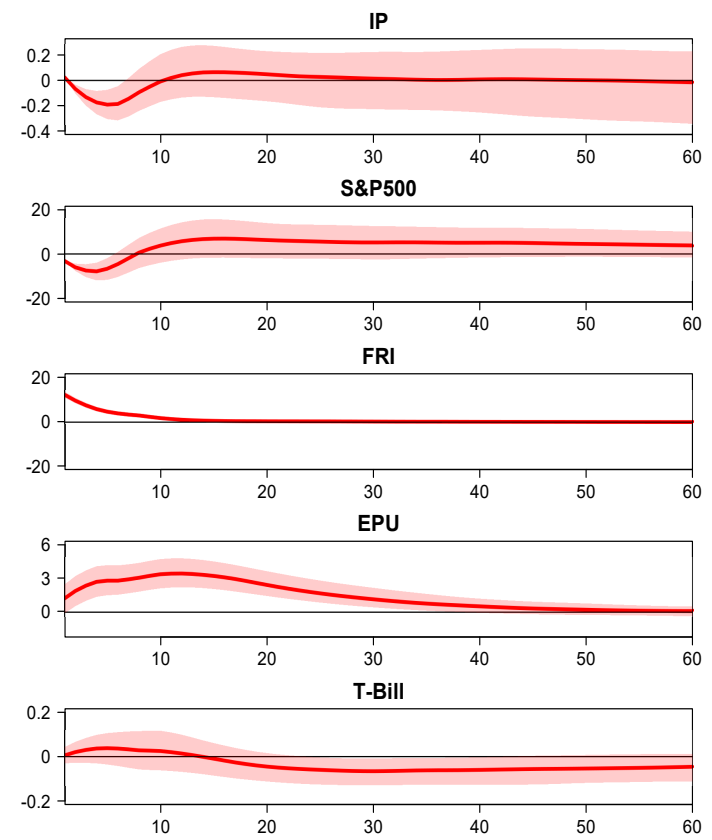

Panel B: FRI ordered 2nd
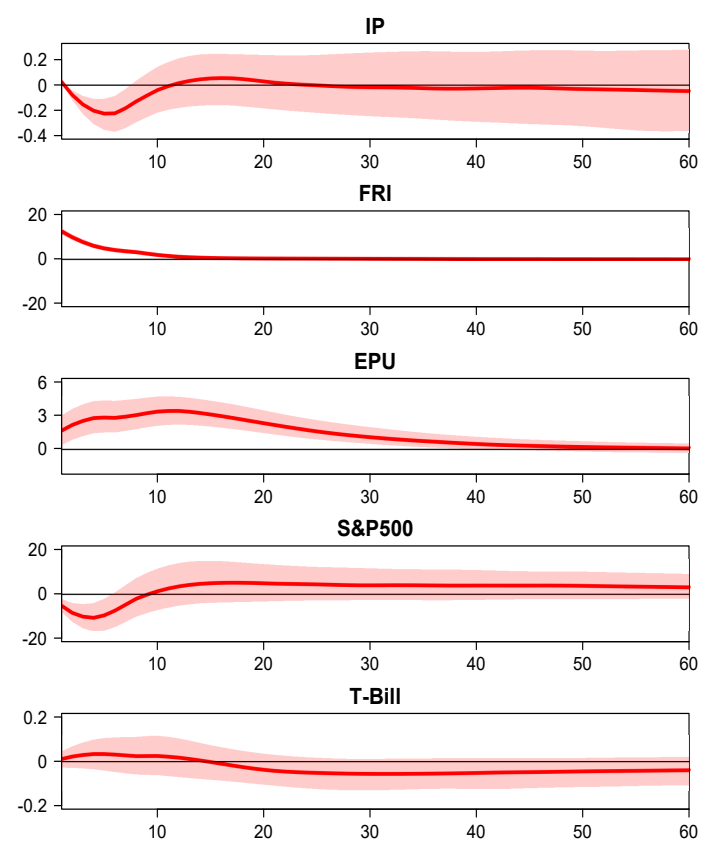

Panel C: FRI ordered 4th
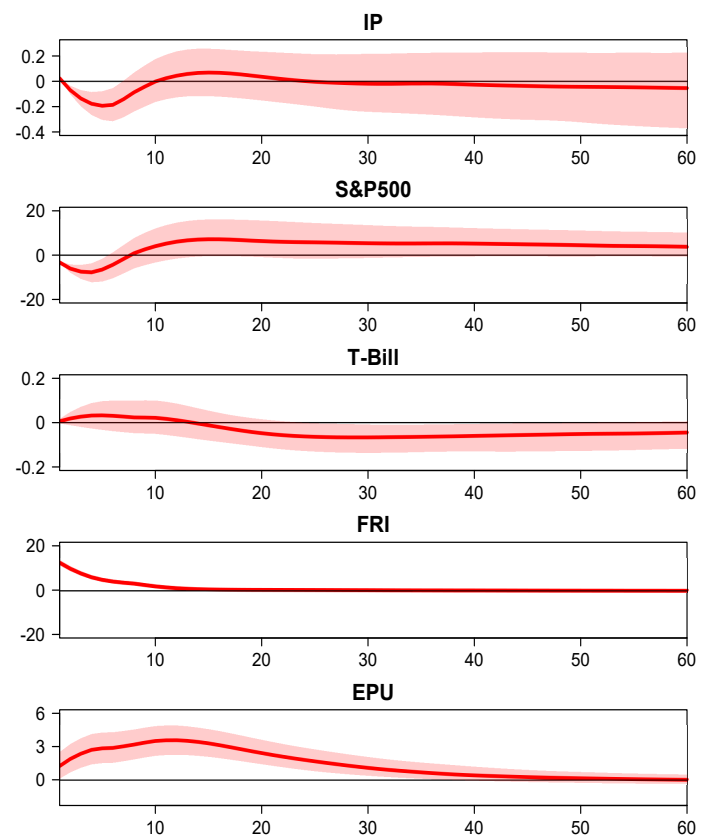


\section{Regulator-manager model}

\section{D.1 Environment}

Firms' true earnings are jointly determined by an aggregate and an idiosyncratic state in each period. There are two values for the aggregate state $a \in\{g, b\}$ with $g>b$ ("good" and "bad"), and two values for the idiosyncratic state $y \in\{h, l\}$ with $h>l$ ("high" and "low"). Each firm's earnings are then ay; we assume a law of large numbers holds for the idiosyncratic state conditional on the aggregate state. The aggregate state is perfectly and costlessly observed by both the regulator and the firm manager, whereas the idiosyncratic state is the private information of the manager; manipulation occurs when the manager reports a high value of $y$ when the true value is low. ${ }^{13}$

The first agent in this model is a regulator; we suppose the objective of the regulator is to maximize the prevalence of truthful reporting, which is consistent with the SEC's mission of "facilitating capital information" 14 and the operating charter of the SEC:

Companies publicly offering securities for investment dollars must tell the public the truth about their businesses, the securities they are selling, and the risks involved in investing.

The regulator chooses the frequency of investigations $\tau$; the cost of investigation is given by the following quadratic form

$$
C(\tau)=C \frac{\tau^{2}}{2}
$$

where $C \geq 0 .{ }^{15}$

The other agents in the model are a continuum of managers who operate individual firms. As noted above, managers choose a report $r \in\{h, l\}$. If a manager produces an inflated report, the manager will be fined in the event of a successful detection; the size of the fine is denoted $F_{m}$. The probability of a fine being leveled given a false report is therefore $\tau p(a)$, where $p=1$ in recessions and $p=\varepsilon$ in expansions.

Managers differ according to the private utility they receive from reported earnings - a report of $r$ delivers $\theta$ ar utils to the managers, where $\theta \sim U N I[0,1]$. We view this assumption as a simple shorthand for a wide variety of reasons that managers may have different valuations

\footnotetext{
${ }^{13}$ Feroz, Park, and Pastena (1991) document that most SEC enforcement actions are aimed at overstatements, the average amount of restatements is negative, and over 75 percent of restatements are negative. Our model thus focuses on upward manipulation.

${ }^{14}$ See the mission of the SEC at http://www.sec.gov/about/whatwedo.shtml.

${ }^{15}$ The quadratic form facilitates a closed-form solution, but our model can accommodate any continuous, strictly increasing, and strictly convex function.
} 
of manipulating earnings, including variation in pay-performance sensitivity, preferences, and the complexity of business operations. The value of $\theta$ is the private information of the manager.

Definition 2 A Bayesian Nash equilibrium for this model is (i) a regulatory investigation policy $\mathbf{T}: R(y) \rightarrow \tau$ that maximizes the objective of the regulator given the reporting strategies of the managers; (ii) a reporting strategy $\mathbf{R}: \tau \rightarrow R(y)$ that maximizes the manager's utility, given the regulatory policy; and (iii) beliefs that are consistent with the actions of other players.

\section{D.2 Optimal reporting}

We first derive the optimal reporting strategy for the managers. Given $(a, y, \theta, \tau)$, each manager chooses the report $r \in\{h, l\}$ to solve

$$
\max _{r \in\{h, l\}}\{\theta a r-\phi(a, y, \tau, r)\}
$$

where

$\phi(a, y, \tau, r)=\left\{\begin{array}{c}0 \quad \text { if } r=y \\ F_{m} \quad \text { if } r \neq y \text { and manipulation is successfully detected } \\ 0 \text { if } r \neq y \text { and manipulation is not investigated or not detected successfully }\end{array}\right.$.

The optimal reporting strategy is

$$
r=\left\{\begin{array}{c}
h \quad \text { if } y=h \\
h \quad \text { if } y=l \text { and } \theta a h-\tau p(a) F_{m} \geq \theta a l \\
l \quad \text { if } y=l \text { and } \theta a h-\tau p(a) F_{m}<\theta a l
\end{array}\right.
$$

Thus, there exists a threshold $\theta$, given by $\widetilde{\theta}=\frac{\tau p(a) F_{m}}{a(h-l)}$, above which managers that get low earnings will manipulate. Clearly, this threshold depends positively on the regulator's investigation choice $\tau$, the success rate for investigations $p(a)$, and the fine amount $F_{m}$, and negatively on the size of misreported earnings $a(h-l)$. From this threshold and the distribution of $\theta$, we can derive the fraction of misreported earnings in the population:

$$
x(a, \tau)=1-\frac{\tau p(a) F_{m}}{a(h-l)} .
$$

\section{D.3 Optimal regulation}

Given the policy for reporting, the regulator chooses $\tau$ to solve

$$
\max _{\tau}\left\{\alpha[1-x(a, \tau)]-\frac{C}{2} \tau^{2}\right\} .
$$


$\alpha>0$ is a preference parameter that measures the effects of "outside pressure" on the regulator to act (we could also have absorbed this parameter into $C$ ); there are stories one could tell that would lead to $\alpha$ varying systematically with the aggregate state $(a){ }^{16}$ Consistent with these stories, Yu and Yu (2011) find that firms engaging in financial fraud spend more on lobbying, and corporate lobbying lowers the likelihood of fraud detection. In our benchmark analysis in Section 3, we assume that alpha $=1$ regardless of the aggregate state for clarity.

\section{D.4 Equilibrium}

We prove that the equilibrium takes the following form.

Proposition 3 The Bayesian Nash equilibrium in given by the regulatory actions

$$
\tau(a)=\frac{\alpha \varepsilon F_{m}}{C a(h-l)}
$$

the prevalence of fraud is

$$
x(a)=1-\frac{\alpha p(a)^{2} F_{m}^{2}}{C a^{2}(h-l)^{2}} .
$$

These functions satisfy

$$
\begin{aligned}
& \tau(g)<\tau(b) \\
& x(g)>x(b) .
\end{aligned}
$$

Managerial incentives to misreport vary with the aggregate state $(a)$ for several reasons. First, the variation in $\tau$ and $p(a)$ implies that detection is lower in good times; then there will be a strong incentive to inflate earnings when $a$ is high. Second, the private benefit from manipulation is increasing in $a$. Third, if $\alpha$ moves countercyclically, then that has an additional effect; during expansions regulators are "not interested" in investigation.

These implications are consistent with the empirical literature. Wang, Winton, and Yu (2007) find that the effect of industry investment on fraud propensity is strongly positive. Cohen and Zarowin (2012) find that the tendency of firms to manipulate earnings upward to beat benchmarks is positively correlated with market-wide conditions. Both facts imply that, when the economy is booming, it is likely that more firms are misstating their earnings upward.

Due to frictions present in detecting fraud, our model generates the following features relevant for asset pricing. First, state-varying detection difficulties give rise to cyclical tendencies in financial regulation. Second, cyclical patterns in managerial manipulation emerge in response to asymmetric regulatory intensities over the business cycle. Third, rational investors who are

\footnotetext{
${ }^{16}$ Stigler (1971) and Peltzman (1976) emphasize the political economy of interest groups in regulatory decisions, in particular regulatory capture by industries. These effects would appear as changes in $\alpha$.
} 
informed about the regulator-managers interaction are uncertain about whether a particular report has been inflated. That is, investors can perfectly infer $x$ given the equilibrium regulatory policy, but they cannot correctly gauge firms' idiosyncratic state. We show in the next section that the relationship between investigation intensity and manipulation frequency together with the unrevealing financial reporting caused by manipulation - has considerable implications for the dynamics of financial markets over business cycles.

\section{E Examples of state variables}

As the monetary penalties upon investigation depend on the number of restated financial statements, the expected number of periods in which the manager inflates earnings since the most recent realization up to now is necessary in characterizing the prices. If there are $N$ consecutive high reports and no low reports after the most recent investigation, a function of $f(N ; \bar{y})$ determines the expected number of periods involving earnings management until the last period. If there is any low report after the last investigation, the sum of $Z$ and $f(N ; \bar{y})$ summarizes the history. In addition, $\gamma$ and $r$ incorporate the information regarding the current true state conveyed by the current report.

To be clear on what each variable represents, a set of clarifying examples is provided in the following. Now let today be $t=10$ and let the last investigation happen at the beginning of $t=5$. Suppose that the true state of $t=4$ is revealed to be $y_{4}$.

- If $\left\{r_{5}, r_{6}, r_{7}, r_{8}, r_{9}, r_{10}\right\}=\{\tilde{h}, \tilde{h}, \tilde{h}, \tilde{l}, \tilde{h}, \tilde{h}\}$, then, at $t=10, Z$ is the expected number of inflated reports during periods 5,6 , and $7 ; N=1$ (it does not include the current period); and $r=\tilde{h} . \bar{y}=l$, because the true state in period 8 is known to be low (recall that all the low reports are honest reports).

- If $\left\{r_{5}, r_{6}, r_{7}, r_{8}, r_{9}, r_{10}\right\}=\{\tilde{h}, \tilde{h}, \tilde{h}, \tilde{h}, \tilde{h}, \tilde{h}\}$, then, at $t=10, Z=0$ (there is no low report after the last investigation until the previous period); $N=5$ (it does not include the current period); and $r=\tilde{h} . \bar{y}=y_{4}$, because it is the known true state before the consecutive high reports.

- If $\left\{r_{5}, r_{6}, r_{7}, r_{8}, r_{9}, r_{10}\right\}=\{\tilde{h}, \tilde{h}, \tilde{h}, \tilde{h}, \tilde{h}, \tilde{l}\}$, then, at $t=10, Z=0$ (there is no low report after the last investigation until the previous period); $N=5$; and $r=\tilde{l} . \bar{y}=y_{4}$, because it is the known true state before the consecutive high reports. Note that $\gamma=0$ at $t=10$, because the current low report is an honest one.

- If $\left\{r_{5}, r_{6}, r_{7}, r_{8}, r_{9}, r_{10}\right\}=\{\tilde{h}, \tilde{h}, \tilde{l}, \tilde{h}, \tilde{l}, \tilde{h}\}$, then, at $t=10, Z$ is the expected number of inflated reports during periods 5,6 , and $8 ; N=0$ (it does not include the current period); and $r=\tilde{h} . \bar{y}=l$, because the true state in period 9 is known to be low (all the low reports 
are honest reports). Note that in the case of $N=0, \bar{y}$ is set to be $y_{t-1}(N=0$ occurs only when the report at $(t-1)$ is low or the investigation happens at the beginning of $t$ ).

- If $\left\{r_{5}, r_{6}, r_{7}, r_{8}, r_{9}, r_{10}\right\}=\{\tilde{h}, \tilde{h}, \tilde{h}, \tilde{h}, \tilde{l}, \tilde{h}\}$, then, at $t=10, Z$ is the expected number of inflated reports during periods $5,6,7$, and $8 ; N=0$; and $r=\tilde{h} . \bar{y}=l$, because the true state in period 9 is known to be low (again, all the low reports are honest reports).

Let today be $t=5$ and let the investigation happen at the beginning of $t=5$.

- If $r_{5}=\tilde{h}$, then $Z=0, N=0, r=\tilde{h}$, and $\bar{y}=y_{4}$.

- If $r_{5}=\tilde{l}$, then $Z=0, N=0, r=\tilde{l}$, and $\bar{y}=y_{4}$.

\section{F Calculation of $f(N ; \bar{y})$ in the model with stochastic in- vestigation}

Let the information set $\mathcal{R}_{N}^{\bar{y}} \equiv\left\{\bar{y}, r_{1}=\tilde{h}, r_{2}=\tilde{h}, \cdots, r_{N}=\tilde{h}\right\} . y_{n}$ represents the true earnings in period $n, \forall n \in\{1,2, \cdots, N\}$. Thus $f(N ; \bar{y})$ can be written as

$$
\begin{aligned}
f(N ; \bar{y})= & \operatorname{Pr}\left[y_{1}=l \mid \mathcal{R}_{N}^{\bar{y}}\right]+\operatorname{Pr}\left[y_{2}=l \mid \mathcal{R}_{N}^{\bar{y}}\right]+\cdots \\
& +\operatorname{Pr}\left[y_{n}=l \mid \mathcal{R}_{N}^{\bar{y}}\right]+\cdots+\operatorname{Pr}\left[y_{N}=l \mid \mathcal{R}_{N}^{\bar{y}}\right]
\end{aligned}
$$

The problem of deriving $f(N ; \bar{y})$ in a recursive way is transformed into an equivalent problem, that is, to recursively derive

$$
\operatorname{Pr}\left[y_{n}=l \mid \mathcal{R}_{N}^{\bar{y}}\right]=1-\operatorname{Pr}\left[y_{n}=h \mid \mathcal{R}_{N}^{\bar{y}}\right], \quad \forall n \in\{1,2, \cdots, N\} .
$$

Note that

$$
\begin{aligned}
& \mathcal{R}_{N}^{h} \equiv\left\{h, r_{1}=\tilde{h}, r_{2}=\tilde{h}, \cdots, r_{N}=\tilde{h}\right\} \\
& \mathcal{R}_{N}^{l} \equiv\left\{l, r_{1}=\tilde{h}, r_{2}=\tilde{h}, \cdots, r_{N}=\tilde{h}\right\}
\end{aligned}
$$

The proof includes two steps. In step $1, \operatorname{Pr}\left[y_{1}=h \mid \mathcal{R}_{1}^{l}\right]$ and $\operatorname{Pr}\left[y_{1}=h \mid \mathcal{R}_{1}^{h}\right]$ are calculated. In step 2, I show that $\operatorname{Pr}\left[y_{n}=h \mid \mathcal{R}_{N+1}^{l}\right]$ and $\operatorname{Pr}\left[y_{n}=h \mid \mathcal{R}_{N+1}^{h}\right], \forall n \in\{1,2, \cdots, N+1\}$, can be calculated using $\operatorname{Pr}\left[y_{n}=h \mid \mathcal{R}_{N}^{l}\right]$ and $\operatorname{Pr}\left[y_{n}=h \mid \mathcal{R}_{N}^{h}\right], \forall n \in\{1,2, \cdots, N\}$. 
As the first step, $\operatorname{Pr}\left[y_{1}=h \mid \mathcal{R}_{1}^{l}\right]$ and $\operatorname{Pr}\left[y_{1}=h \mid \mathcal{R}_{1}^{h}\right]$ are derived as follows.

$$
\begin{aligned}
\operatorname{Pr}\left[y_{1}=h \mid \mathcal{R}_{1}^{l}\right] & =\operatorname{Pr}\left[y_{1}=h \mid \bar{y}=l, r_{1}=\tilde{h}\right] \\
& =\frac{\operatorname{Pr}\left[y_{1}=h, r_{1}=\tilde{h} \mid \bar{y}=l\right]}{\operatorname{Pr}\left[r_{1}=\tilde{h} \mid \bar{y}=l\right]} \\
& =\frac{\pi_{l h}}{\pi_{l h}+\left(1-\pi_{l h}\right) x_{a}}, \\
\operatorname{Pr}\left[y_{1}=h \mid \mathcal{R}_{1}^{h}\right] & =\operatorname{Pr}\left[y_{1}=h \mid \bar{y}=h, r_{1}=\tilde{h}\right] \\
& =\frac{\operatorname{Pr}\left[y_{1}=h, r_{1}=\tilde{h} \mid \bar{y}=h\right]}{\operatorname{Pr}\left[r_{1}=\tilde{h} \mid \bar{y}=h\right]} \\
& =\frac{\pi_{h h}}{\pi_{h h}+\left(1-\pi_{h h}\right) x_{a}},
\end{aligned}
$$

where $a \in\{b, g\}$ represents the aggregate state in period 1 .

In step 2, I first show that $\operatorname{Pr}\left[y_{n}=h \mid \mathcal{R}_{N+1}^{l}\right]$ can be calculated if $\operatorname{Pr}\left[y_{n}=h \mid \mathcal{R}_{N}^{l}\right]$ is known. For $n \in\{1,2, \cdots, N+1\}$,

$$
\operatorname{Pr}\left[y_{n}=h \mid \mathcal{R}_{N}^{l}, r_{N+1}=\tilde{h}\right]=\frac{\operatorname{Pr}\left[y_{n}=h, r_{N+1}=\tilde{h} \mid \mathcal{R}_{N}^{l}\right]}{\operatorname{Pr}\left[r_{N+1}=\tilde{h} \mid \mathcal{R}_{N}^{l}\right]} .
$$

The denominator in $(3), \operatorname{Pr}\left[r_{N+1}=\tilde{h} \mid \mathcal{R}_{N}^{l}\right]$, is derived as the following.

$$
\begin{aligned}
\operatorname{Pr}\left[r_{N+1}=\tilde{h} \mid \mathcal{R}_{N}^{l}\right]= & \operatorname{Pr}\left[r_{N+1}=\tilde{h}, y_{N+1}=h \mid \mathcal{R}_{N}^{l}\right]+\operatorname{Pr}\left[r_{N+1}=\tilde{h}, y_{N+1}=l \mid \mathcal{R}_{N}^{l}\right] \\
= & \operatorname{Pr}\left[r_{N+1}=\tilde{h} \mid y_{N+1}=h, \mathcal{R}_{N}^{l}\right] \times \operatorname{Pr}\left[y_{N+1}=h \mid \mathcal{R}_{N}^{l}\right] \\
& +\operatorname{Pr}\left[r_{N+1}=\tilde{h} \mid y_{N+1}=l, \mathcal{R}_{N}^{l}\right] \times \operatorname{Pr}\left[y_{N+1}=l \mid \mathcal{R}_{N}^{l}\right] \\
= & \operatorname{Pr}\left[y_{N+1}=h \mid \mathcal{R}_{N}^{l}\right]+x_{a}\left[1-\operatorname{Pr}\left[y_{N+1}=h \mid \mathcal{R}_{N}^{l}\right]\right]
\end{aligned}
$$

where $a \in\{b, g\}$ represents the aggregate state in period $N+1$, and

$$
\begin{aligned}
\operatorname{Pr}\left[y_{N+1}=h \mid \mathcal{R}_{N}^{l}\right]= & \operatorname{Pr}\left[y_{N+1}=h, y_{N}=h \mid \mathcal{R}_{N}^{l}\right]+\operatorname{Pr}\left[y_{N+1}=h, y_{N}=l \mid \mathcal{R}_{N}^{l}\right] \\
= & \operatorname{Pr}\left[y_{N+1}=h \mid y_{N}=h, \mathcal{R}_{N}^{l}\right] \times \operatorname{Pr}\left[y_{N}=h \mid \mathcal{R}_{N}^{l}\right] \\
& +\operatorname{Pr}\left[y_{N+1}=h \mid y_{N}=l, \mathcal{R}_{N}^{l}\right] \times \operatorname{Pr}\left[y_{N}=l \mid \mathcal{R}_{N}^{l}\right] \\
= & \pi_{h h} \operatorname{Pr}\left[y_{N}=h \mid \mathcal{R}_{N}^{l}\right]+\pi_{l h}\left[1-\operatorname{Pr}\left[y_{N}=h \mid \mathcal{R}_{N}^{l}\right]\right] .
\end{aligned}
$$

As $\operatorname{Pr}\left[y_{N}=h \mid \mathcal{R}_{N}^{l}\right]$ is known from the supposition, this can be calculated. The denominator is obtained

$$
\begin{aligned}
\operatorname{Pr}\left[r_{N+1}=\tilde{h} \mid \mathcal{R}_{N}^{l}\right]= & \pi_{h h} \operatorname{Pr}\left[y_{N}=h \mid \mathcal{R}_{N}^{l}\right]+\pi_{l h}\left[1-\operatorname{Pr}\left[y_{N}=h \mid \mathcal{R}_{N}^{l}\right]\right] \\
& +x_{a}\left\{1-\pi_{h h} \operatorname{Pr}\left[y_{N}=h \mid \mathcal{R}_{N}^{l}\right]-\pi_{l h}\left[1-\operatorname{Pr}\left[y_{N}=h \mid \mathcal{R}_{N}^{l}\right]\right]\right\}
\end{aligned}
$$


where $a \in\{b, g\}$ represents the aggregate state in period $N+1$.

Now let us consider the numerator in (3). For $n=N+1, \operatorname{Pr}\left[y_{N+1}=h, r_{N+1}=\tilde{h} \mid \mathcal{R}_{N}^{l}\right]$ can be rewritten as

$$
\begin{aligned}
\operatorname{Pr}\left[y_{N+1}=h, r_{N+1}=\tilde{h} \mid \mathcal{R}_{N}^{l}\right] & =\operatorname{Pr}\left[r_{N+1}=\tilde{h} \mid y_{N+1}=h, \mathcal{R}_{N}^{l}\right] \times \operatorname{Pr}\left[y_{N+1}=h \mid \mathcal{R}_{N}^{l}\right] \\
& =\operatorname{Pr}\left[y_{N+1}=h \mid \mathcal{R}_{N}^{l}\right],
\end{aligned}
$$

where $\operatorname{Pr}\left[y_{N+1}=h \mid \mathcal{R}_{N}^{l}\right]$ is derived in (4).

For $n \in\{1,2, \cdots, N\}$, the numerator $\operatorname{Pr}\left[y_{n}=h, r_{N+1}=\tilde{h} \mid \mathcal{R}_{N}^{l}\right]$ can be rewritten as

$$
\operatorname{Pr}\left[y_{n}=h, r_{N+1}=\tilde{h} \mid \mathcal{R}_{N}^{l}\right]=\operatorname{Pr}\left[r_{N+1}=\tilde{h} \mid y_{n}=h, \mathcal{R}_{N}^{l}\right] \times \operatorname{Pr}\left[y_{n}=h \mid \mathcal{R}_{N}^{l}\right] .
$$

Here, $\operatorname{Pr}\left[y_{n}=h \mid \mathcal{R}_{N}^{l}\right]$ is known from the supposition. Now we only need to check if $\operatorname{Pr}\left[r_{N+1}=\right.$ $\left.\tilde{h} \mid y_{n}=h, \mathcal{R}_{N}^{l}\right]$ can be calculated. I rewrite

$$
\operatorname{Pr}\left[r_{N+1}=\tilde{h} \mid y_{n}=h, \mathcal{R}_{N}^{l}\right]=\Theta+\Lambda,
$$

where

$$
\begin{aligned}
\Theta & =\operatorname{Pr}\left[r_{N+1}=\tilde{h}, y_{N+1}=h \mid y_{n}=h, \mathcal{R}_{N}^{l}\right] \\
& =\operatorname{Pr}\left[r_{N+1}=\tilde{h} \mid y_{N+1}=h, y_{n}=h, \mathcal{R}_{N}^{l}\right] \times \operatorname{Pr}\left[y_{N+1}=h \mid y_{n}=h, \mathcal{R}_{N}^{l}\right] \\
& =1 \times \operatorname{Pr}\left[y_{N+1}=h \mid y_{n}=h, \mathcal{R}_{N}^{l}\right] \\
& =\operatorname{Pr}\left[y_{N+1}=h \mid y_{n}=h, \mathcal{R}_{N}^{l}\right], \\
\Lambda & =\operatorname{Pr}\left[r_{N+1}=\tilde{h}, y_{N+1}=l \mid y_{n}=h, \mathcal{R}_{N}^{l}\right] \\
& =\operatorname{Pr}\left[r_{N+1}=\tilde{h} \mid y_{N+1}=l, y_{n}=h, \mathcal{R}_{N}^{l}\right] \times \operatorname{Pr}\left[y_{N+1}=l \mid y_{n}=h, \mathcal{R}_{N}^{l}\right] \\
& =x_{a}\left[1-\operatorname{Pr}\left[y_{N+1}=h \mid y_{n}=h, \mathcal{R}_{N}^{l}\right]\right] \\
& =x_{a}[1-\Theta]
\end{aligned}
$$

where $a \in\{b, g\}$ represents the aggregate state in period $N+1$.

If $n=N$, it is straightforward to determine that

$$
\operatorname{Pr}\left[y_{N+1}=h \mid y_{n}=h, \mathcal{R}_{N}^{l}\right]=\pi_{h h} .
$$

Now let us consider $\operatorname{Pr}\left[y_{N+1}=h \mid y_{n}=h, \mathcal{R}_{N}^{l}\right]$ if $n<N$. Because actual earnings $y$ follow a Markov process, all the past information is fully summarized in the most recent realization, and the prior realizations are informationally irrelevant. Thus,

$$
\begin{aligned}
\operatorname{Pr}\left[y_{N+1}=h \mid y_{n}=h, \mathcal{R}_{N}^{l}\right] & =\operatorname{Pr}\left[y_{N+1}=h \mid y_{n}=h, \bar{y}=l, r_{1}=\tilde{h}, \cdots, r_{N}=\tilde{h}\right], \\
& =\operatorname{Pr}\left[y_{N+1}=h \mid \bar{y}=h, r_{n+1}=\tilde{h}, \cdots, r_{N}=\tilde{h}\right]
\end{aligned}
$$


and

$$
\operatorname{Pr}\left[y_{N+1}=h \mid \bar{y}=h, r_{n+1}=\tilde{h}, \cdots, r_{N}=\tilde{h}\right]=\operatorname{Pr}\left[y_{N-n+1} \mid \bar{y}=h, r_{1}=\tilde{h}, \cdots, r_{N-n}=\tilde{h}\right] .
$$

Recall that $\mathcal{R}_{N-n}^{h} \equiv\left\{\bar{y}=h, r_{1}=\tilde{h}, \cdots, r_{N-n}=\tilde{h}\right\}$. Therefore,

$$
\operatorname{Pr}\left[y_{N+1}=h \mid y_{n}=h, \mathcal{R}_{N}^{l}\right]= \begin{cases}\operatorname{Pr}\left[y_{N-n+1}=h \mid \mathcal{R}_{N-n}^{h}\right] & \text { if } n<N \\ \pi_{h h} & \text { if } n=N .\end{cases}
$$

and

$$
\begin{aligned}
\operatorname{Pr}\left[y_{N-n+1}=h \mid \mathcal{R}_{N-n}^{h}\right]= & \operatorname{Pr}\left[y_{N-n+1}=h, y_{N-n}=h \mid \mathcal{R}_{N-n}^{h}\right]+\operatorname{Pr}\left[y_{N-n+1}=h, y_{N-n}=l \mid \mathcal{R}_{N-n}^{h}\right] \\
= & \operatorname{Pr}\left[y_{N-n+1}=h \mid y_{N-n}=h, \mathcal{R}_{N-n}^{h}\right] \times \operatorname{Pr}\left[y_{N-n}=h \mid \mathcal{R}_{N-n}^{h}\right] \\
& +\operatorname{Pr}\left[y_{N-n+1}=h \mid y_{N-n}=l, \mathcal{R}_{N-n}^{h}\right] \times \operatorname{Pr}\left[y_{N-n}=l \mid \mathcal{R}_{N-n}^{h}\right] \\
= & \pi_{h h} \operatorname{Pr}\left[y_{N-n}=h \mid \mathcal{R}_{N-n}^{h}\right]+\pi_{l h}\left[1-\operatorname{Pr}\left[y_{N-n}=h \mid \mathcal{R}_{N-n}^{h}\right]\right],
\end{aligned}
$$

where $\operatorname{Pr}\left[y_{N-n}=h \mid \mathcal{R}_{N-n}^{h}\right]$ is known from the supposition, since $N-n<N$. Therefore, $\Theta$ and $\Lambda$ can be both calculated. Hence, the numerator in (3) can be derived following this procedure. The numerator is obtained

$$
\begin{aligned}
& \operatorname{Pr}\left[y_{n}=h, r_{N+1}=\tilde{h} \mid \mathcal{R}_{N}^{l}\right]= \\
& \begin{cases}\pi_{h h} \operatorname{Pr}\left[y_{N}=h \mid \mathcal{R}_{N}^{l}\right]+\pi_{l h}\left[1-\operatorname{Pr}\left[y_{N}=h \mid \mathcal{R}_{N}^{l}\right]\right] & \text { if } n=N+1, \\
\operatorname{Pr}\left[y_{N}=h \mid \mathcal{R}_{N}^{l}\right]\left[\pi_{h h}+x_{a}\left(1-\pi_{h h}\right)\right] & \text { if } n=N, \\
\operatorname{Pr}\left[y_{n}=h \mid \mathcal{R}_{N}^{l}\right]\left\{\pi_{h h} \operatorname{Pr}\left[y_{N-n}=h \mid \mathcal{R}_{N-n}^{h}\right]+\right. & \text { if } n<N . \\
\pi_{l h}\left[1-\operatorname{Pr}\left[y_{N-n}=h \mid \mathcal{R}_{N-n}^{h}\right]\right] & \\
\left.+x_{a}\left\{1-\pi_{h h} \operatorname{Pr}\left[y_{N-n}=h \mid \mathcal{R}_{N-n}^{h}\right]-\pi_{l h}\left[1-\operatorname{Pr}\left[y_{N-n}=h \mid \mathcal{R}_{N-n}^{h}\right]\right]\right\}\right\}, & \end{cases}
\end{aligned}
$$

where $a \in\{b, g\}$ represents the aggregate state in period $N+1$.

Now combining the expressions (5) and (9), it has been shown that $\operatorname{Pr}\left[y_{n}=h \mid \mathcal{R}_{N}^{l}, r_{N+1}=\tilde{h}\right]$ can be calculated using $\operatorname{Pr}\left[y_{n}=h \mid \mathcal{R}_{N}^{l}, r_{N}=\tilde{h}\right]$. The same procedure can be repeated for $\operatorname{Pr}\left[y_{n}=h \mid \mathcal{R}_{N}^{h}, r_{N+1}=\tilde{h}\right]$ as follows.

$$
\operatorname{Pr}\left[y_{n}=h \mid \mathcal{R}_{N}^{h}, r_{N+1}=\tilde{h}\right]=\frac{\operatorname{Pr}\left[y_{n}=h, r_{N+1}=\tilde{h} \mid \mathcal{R}_{N}^{h}\right]}{\operatorname{Pr}\left[r_{N+1}=\tilde{h} \mid \mathcal{R}_{N}^{h}\right]} .
$$


where the denominator is

$$
\begin{aligned}
\operatorname{Pr}\left[r_{N+1}=\tilde{h} \mid \mathcal{R}_{N}^{h}\right]= & \pi_{h h} \operatorname{Pr}\left[y_{N}=h \mid \mathcal{R}_{N}^{h}\right]+\pi_{l h}\left[1-\operatorname{Pr}\left[y_{N}=h \mid \mathcal{R}_{N}^{h}\right]\right] \\
& +x\left\{1-\pi_{h h} \operatorname{Pr}\left[y_{N}=h \mid \mathcal{R}_{N}^{h}\right]-\pi_{l h}\left[1-\operatorname{Pr}\left[y_{N}=h \mid \mathcal{R}_{N}^{h}\right]\right]\right\} .
\end{aligned}
$$

and the numerator is

$$
\begin{aligned}
& \operatorname{Pr}\left[y_{n}=h, r_{N+1}=\tilde{h} \mid \mathcal{R}_{N}^{h}\right]= \\
& \begin{cases}\pi_{h h} \operatorname{Pr}\left[y_{N}=h \mid \mathcal{R}_{N}^{h}\right]+\pi_{l h}\left[1-\operatorname{Pr}\left[y_{N}=h \mid \mathcal{R}_{N}^{h}\right]\right] & \text { if } n=N+1, \\
\operatorname{Pr}\left[y_{N}=h \mid \mathcal{R}_{N}^{h}\right]\left[\pi_{h h}+x_{a}\left(1-\pi_{h h}\right)\right] & \text { if } n=N, \\
\operatorname{Pr}\left[y_{n}=h \mid \mathcal{R}_{N}^{h}\right]\left\{\pi_{h h} \operatorname{Pr}\left[y_{N-n}=h \mid \mathcal{R}_{N-n}^{h}\right]+\right. & \text { if } n<N . \\
\pi_{l h}\left[1-\operatorname{Pr}\left[y_{N-n}=h \mid \mathcal{R}_{N-n}^{h}\right]\right] \\
\left.+x_{a}\left\{1-\pi_{h h} \operatorname{Pr}\left[y_{N-n}=h \mid \mathcal{R}_{N-n}^{h}\right]-\pi_{l h}\left[1-\operatorname{Pr}\left[y_{N-n}=h \mid \mathcal{R}_{N-n}^{h}\right]\right]\right\}\right\},\end{cases}
\end{aligned}
$$

where $a \in\{b, g\}$ represents the aggregate state in period $N+1$.

\section{G Stock returns and the business cycle}

In this part we document a systematic relationship between recessions and the probability of stock crashes. Here, we present two measures of a stock crash. The first is taken from Barro and Ursua (2009) - a crash is a realized real return of less than -25 percent. In Figure 16, we see that, while the correlation of crash risk (frequency of crashes) with NBER recessions is low (0.07), there are pronounced spikes during each recession; the low correlation is then attributable to the smaller variation during expansions.

Figure 17 uses a measure of crash risk from Jin and Myers (2006), denoted COUNT, that captures the measured number of returns that exceed $k$ standard deviations below the mean, with $k$ chosen to generate frequencies of 0.1 percent in a log-normal distribution. ${ }^{17} \mathrm{~A}$ high value of COUNT indicates high crash risk. We can see that not only is crash risk positively correlated with NBER recessions (0.39), it also tends to spike at the onset of recessions. If we look at GDP growth, we find a similar story - the correlation between crash risk and output is -0.42 . Note that this increase is not confined to the financial crisis of 2007; similar spikes occur during other recessions as well, such as the OPEC recession of 1973-1974 and the Volcker deflation.

\footnotetext{
${ }^{17}$ Using a threshold of 0.01 percent does not change the correlation.
} 
We also want to point here to two other features of stock returns. First, the data display negative skewness $(-0.139)$, showing that big downward movements (crashes) are more likely than big upward movements. Second, volatility is countercyclical - volatility in recessions is on average 1.39 times as large as in expansions.

Figure 16: Barro-Ursua Crash Risk

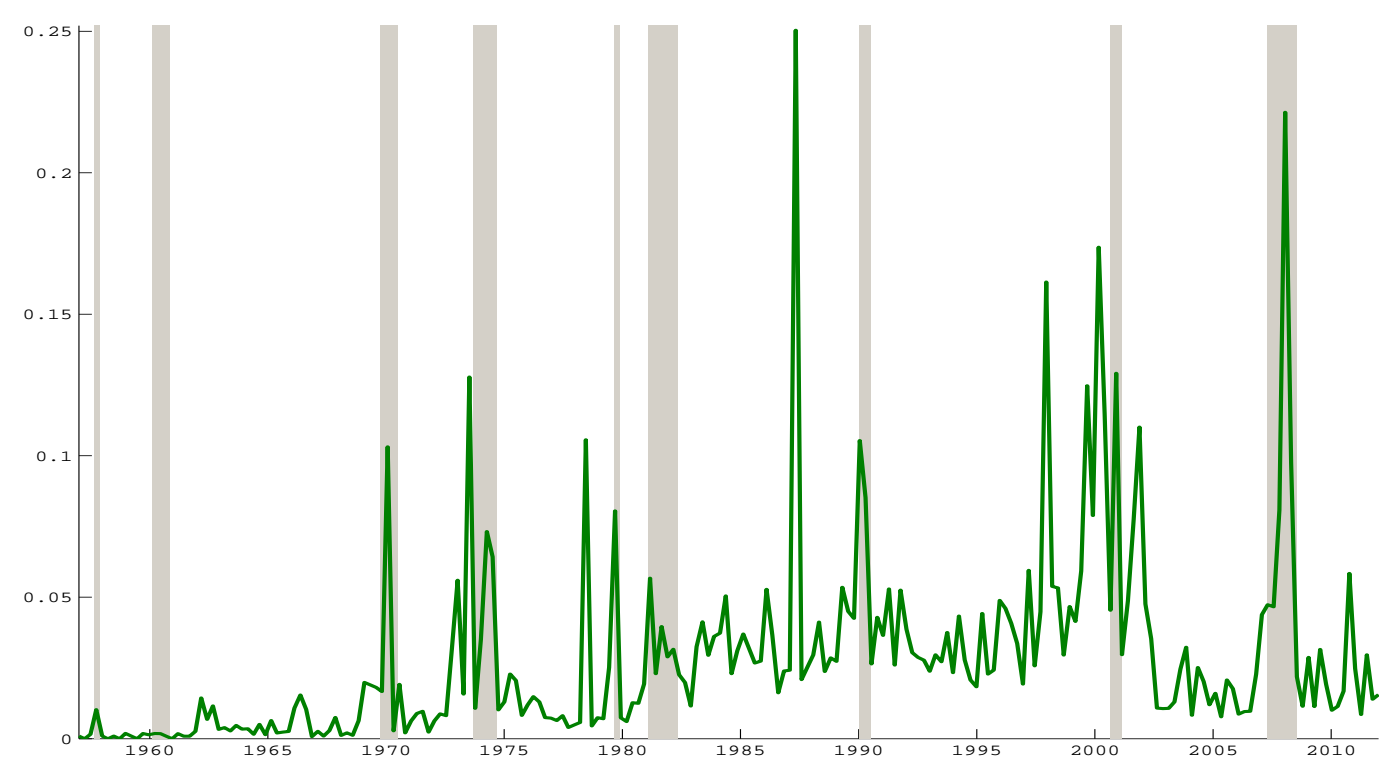

Figure 17: Jin-Myers Crash Risk

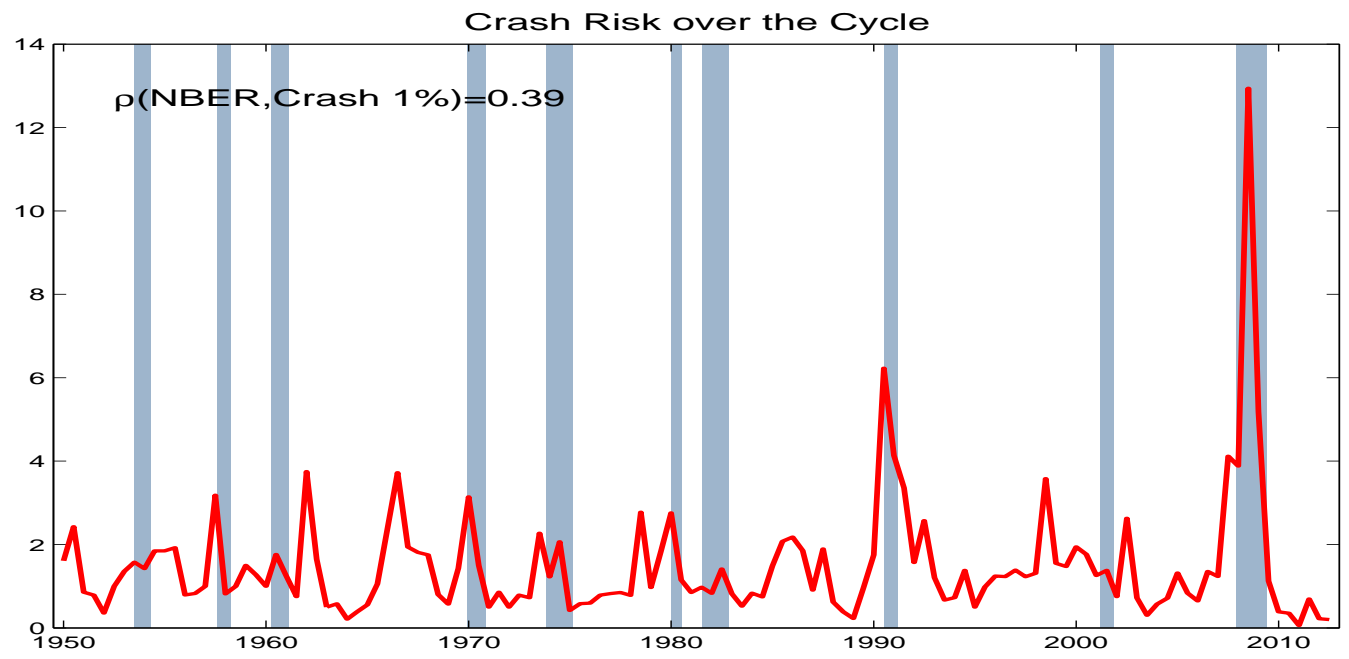

